\title{
Stable isotope analyses of rock hyrax faecal pellets, hyraceum and associated vegetation in southern Africa: implications for dietary ecology and palaeoenvironmental reconstructions
}

\author{
Andrew S. Carr ${ }^{a}$, Brian M. Chase ${ }^{b}$, Arnoud Booma ${ }^{a}$ Javier Medina-Sanchez ${ }^{a}$ \\ aDepartment of Geography, University of Leicester, Leicester, LE1 7RH, UK.

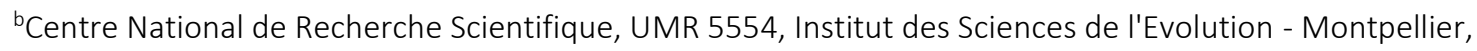 \\ Département Paléoenvironnements, Université Montpellier, Bat.22, CC061, Place Eugène Bataillon, 34095 \\ Montpellier, cedex 5, France.
}

*Correspondance to: asc18@leicester.ac.uk 


\section{Abstract}

2 Rock hyrax middens are important palaeoenvironmental archives in southern Africa. Carbon and 3 nitrogen isotope measurements on middens (hyraceum) are key components of climate 4 reconstructions, but their interpretations require refinement. Although $\delta^{15} \mathrm{~N}$ in hyraceum often 5 correlates with independent proxies for palaeo-aridity, the impact of dietary and physiological 6 controls on hyraceum $\delta^{15} \mathrm{~N}$ remain to be resolved. We analyse $\delta^{13} \mathrm{C}$ and $\delta^{15} \mathrm{~N}$ in plant foliage, hyrax 7 faecal pellets and hyraceum from 21 sites across southern Africa. Faeces are generally depleted in ${ }^{13} \mathrm{C}$ $8 \quad\left(\delta^{13} \mathrm{C}\right.$ typically $\left.<-20 \%\right)$, suggesting significant browsing. Grazing is rarely dominant and probably 9 occurs only when palatable grass is available. Variability in faecal and foliar $\delta^{15} \mathrm{~N}$ is large, but foliar $\delta^{15} \mathrm{~N}$ 10 is positively correlated with faecal $\delta^{15} \mathrm{~N}$. The diet-faeces $\delta^{15} \mathrm{~N}$ offset is uncorrelated with climate 11 (aridity), but is correlated with $\% \mathrm{~N}$ in faeces. Faecal $\delta^{15} \mathrm{~N}$ is positively correlated with modern 12 hyraceum $\delta^{15} \mathrm{~N}$, and the relationships with aridity index for foliar and faecal (body tissue) $\delta^{15} \mathrm{~N}$ are 13 comparable. These observations implicate diet as a significant control on hyraceum $\delta^{15} \mathrm{~N}$ and we observe no strong evidence for metabolic controls on hyraceum $\delta^{15} \mathrm{~N}$. More data are required to refine these relationships, but these observations are consistent with palaeoenvironmental interpretations of midden $\delta^{15} \mathrm{~N}$ and $\delta^{13} \mathrm{C}$.

Keywords: Dassie, urine, $C_{3} / C_{4}$ plants, herbivore, carbon, nitrogen 
Highlights

- Rock hyraxes are generally browsers, but will graze when grass is available.

- Significant correlation between foliar (dietary) $\delta^{15} \mathrm{~N}$ and faecal $\delta^{15} \mathrm{~N}$.

- Significant correlation between faecal $\delta^{15} \mathrm{~N}$ and hyraceum $\delta^{15} \mathrm{~N}$.

- Diet-faecal $\delta^{15} \mathrm{~N}$ offset uncorrelated with climate.

24

- Significant correlations between faecal $\delta^{15} \mathrm{~N}$, foliar $\delta^{15} \mathrm{~N}$ and aridity index. 


\section{Introduction}

The communal latrines (middens) of the rock hyrax (Procavia capensis) have emerged as a key palaeoenvironmental archive for desert regions in southern Africa (Scott and Bousman, 1990; GilRomera et al., 2006; Chase et al., 2012). Several studies have developed palaeoclimatic records using sequential analysis of stable carbon and nitrogen isotopes through stratified hyraceum, the crystallised urinary material (cf. faecal pellets) that forms many hyrax middens (Scott and Vogel, 2000; Chase et al., 2009; 2010; 2011; 2012; 2013; 2015a; 2015b). Changes in hyraceum isotopic signals have been inferred to largely relate to the stable isotope composition of the animal's diet and thus, to environmental controls on plant isotopic composition in the midden environs (Chase et al., 2012). It has been argued that this interpretation is supported by facets of the midden geochemistry (Carr et al., 2010) and by: 1) the close correlations in temporal isotopic trends between discrete midden (colony) records (Chase et al., 2010); 2) correlations of such trends with independent palaeoenvironmental archives, which furthermore show the isotopically opposite responses to those predicted by dominantly metabolic controls on urine stable isotope composition (Chase et al., 2009; 2011, 2013; 2015b); and 3) good correlations between isotope and pollen data from the same midden (Chase et al., 2015a; Chase et al. 2015b).

Notwithstanding, the fundamental isotope systematics of the diet-herbivore system within rock hyrax habitats remain to be fully elucidated. Observational data pertaining to feeding behaviour exist for several hyrax species (Procavia johnstoni and Heterohyrax brucei; Hoeck, 1975), including Procavia capensis (Lensing, 1983; Fourie, 1983), but isotopic data from materials other than hyraceum are limited (e.g. DeNiro and Epstein, 1978). The aim of the present work is to significantly expand our understanding of the dietary variability and the isotope ecology of the rock hyrax (Procavia capensis) via an extensive study of stable carbon and nitrogen isotopes relating to the animal's diet (derived from faecal pellets) and to their potential diet (derived from plants around hyrax colonies) across a range of climatic conditions. The latter data are also of wider value as systematically-derived $\delta^{13} \mathrm{C}$ and $\delta^{15} \mathrm{~N}$ data from contemporary soils and plants in southern Africa are still relatively limited (cf. Heaton et al., 1986; Aranibar et al. 2008). Such data provide important benchmarking and calibration information for various aspects of palaeoenvironmental research in this region (e.g. Codron et al. 2013).

\section{Carbon and nitrogen isotopes in faeces}

The stable carbon and nitrogen isotope compositions of animal tissues (e.g. hair and bone) and faecal matter provide insights into herbivore diet (Ambrose and DeNiro, 1986a; Codron et al., 2005; Codron and Codron, 2009; Botha and Stock, 2005; Sponheimer et al., 2003a). An assessment of dietary 
preferences using faeces is particularly useful as information is obtained without disturbing the animal and, unlike hard tissue it allows insights into feeding behaviour and dietary variability (Sponheimer et al., 2003a; Codron et al 2005). In much of southern Africa, warm growing season, aridity-adapted $\mathrm{C}_{4}$ grasses are preferentially consumed by grazers and exhibit leaf tissue $\delta^{13} \mathrm{C}$ in the range -10 to $-14 \%$. $C_{3}$ plant tissue $\delta^{13} \mathrm{C}$ typically measures -28 to $-25 \%$ (Vogel et al., 1978; Codron et al., 2005; 2013). Given such a separation, analysis of herbivore faecal $\delta^{13} \mathrm{C}$ allows grazing, browsing and mixed feeding behaviours to be differentiated (Sponheimer et al. 2003a; Codron and Codron, 2009).

The nitrogen isotope signature of herbivore faeces is more complex to interpret. Body tissue $\delta^{15} \mathrm{~N}$ may be affected by several factors, including trophic level (Schoeninger and DeNiro, 1984), diet (plant isotopic composition, food quality, protein content (Sponheimer et al., 2003b/c)) and physiology (e.g. water stress (Ambrose and DeNiro, 1986b; Ambrose, 1991) or hind / foregut fermentation (Sealy et al., 1987; Codron et al., 2009)). A tendency for higher herbivore body tissue $\delta^{15} \mathrm{~N}$ under arid conditions has been associated with physiological processes related to water conservation. Specifically, it has been proposed that drought-tolerant herbivores excrete more ${ }^{14} \mathrm{~N}$ enriched urea and thus have higher body tissue $\delta^{15} \mathrm{~N}$ under conditions of drought stress (Ambrose and DeNiro, 1986a; Ambrose and DeNiro, 1986b; Ambrose and DeNiro, 1987; Sealy et al., 1987). Such physiological explanations were originally motivated by the combined observations of a negative correlation between rainfall and $\delta^{15} \mathrm{~N}$ in bones and the apparent absence of any relationship between plant (i.e. diet) $\delta^{15} \mathrm{~N}$ and rainfall (Ambrose and DeNiro, 1987; Heaton et al., 1986). Subsequently, multiple studies have demonstrated significant, albeit scattered, relationships between foliar $\delta^{15} \mathrm{~N}$ and aridity (e.g. Craine et al., 2009; Hartman and Danin, 2010; Murphy and Bowman; 2006; Szpac et al., 2013), and others have specifically considered the relationship between plant and herbivore $\delta^{15} \mathrm{~N}$, finding that both increase with aridity, with a $2-3 \%$ offset attributable to trophic level enrichment, but no progressive increase in herbivore $\delta^{15} \mathrm{~N}$ relative to plant $\delta^{15} \mathrm{~N}$ (Schwarcz et al., 1999; Hartman, 2011; Murphy and Bowman, 2006). While the precise mechanisms for such enrichment in plants (i.e. dietary source) are still debated (Craine et al., 2015) these findings imply that body tissue $\delta^{15} \mathrm{~N}$ in herbivores is potentially influenced by diet.

Rock hyraxes are generally independent of water (i.e. drought-tolerant), but when available, they will drink freely (Skinner and Chimimba, 2005). In South Africa hyrax bone collagen $\delta^{15} \mathrm{~N}$ has been reported to be relatively high compared to other herbivores (up to 17\%; Sealy et al., 1987). In hyraceum from rock hyrax middens $\delta^{15} \mathrm{~N}$ ranges from $-2 \%$, (at the De Rif midden in the Cederberg Mountains north of Cape Town; Chase et al., 2011) to $+20 \%$ (at Austerlitz in the arid northern Namib Desert; Chase et al., 2010) and can vary by up to $5 \%$ within stratified hyraceum during the Holocene 
(e.g. Chase et al., 2009; 2015a). As $\delta^{15} \mathrm{~N}$ analysis of hyrax middens has become an important component of recent palaeoenvironmental studies, there is an impetus to refine our understanding of $\delta^{15} \mathrm{~N}$ dynamics in rock hyraxes and their ecosystems. More generally, control(s) on herbivore tissue $\delta^{15} \mathrm{~N}$ remain to be fully elucidated (e.g. Hartman 2011). As a first step to addressing this we assess: 1 ) the natural variability in hyrax faecal $\delta^{15} \mathrm{~N}$ within and between hyrax colonies, 2) the relationship between faecal $\delta^{15} \mathrm{~N}$ and dietary $\delta^{15} \mathrm{~N}$ (i.e. foliar $\delta^{15} \mathrm{~N}$ from plants surrounding colonies), and 3) the relationship between faecal $\delta^{15} \mathrm{~N}$ and hyraceum $\delta^{15} \mathrm{~N}$. These are considered across a variety of biomes and climatic zones in southern Africa. Although a total understanding of ${ }^{15} \mathrm{~N}$ dynamics in any animal may require laboratory experimentation (e.g. Sponheimer et al., 2003a, 2003b), we can hypothesise that if $\delta^{15} \mathrm{~N}$ variability within hyrax middens is largely an environmental signal derived from the animal's diet, modern faecal and hyraceum $\delta^{15} \mathrm{~N}$ should correlate with dietary (local vegetation) $\delta^{15} \mathrm{~N}$ (with some as yet undetermined trophic level offset).

\section{Methods and materials}

\section{Study sites and sampling}

Rock hyrax faecal pellets were collected from 21 sites across southern Africa. These sites span both the summer and winter rainfall zones (Table $\mathbf{1}$ and Figure $\mathbf{1}$ ) and include sites in the Fynbos, Savanna, Succulent Karoo, Grassland and Nama Karoo biomes. Sites in the Fynbos biome are all located in the montane fynbos of the Cape Fold Belt Mountains. Sites in the west of the biome (De Rif [DR], Pakhuis Pass [PP], and Kliprandfontein [KRF]; figures $\mathbf{1}$ and 2f) lie in the Cederberg Mountains and are characterised by $>75 \%$ winter rainfall and shrubby $C_{3}$ vegetation containing largely asteraceous, restioid and proteoid elements. Fynbos sites in the southern Cape Fold Belt Mountains (Seweweekspoort [SWP] Meiringspoort [MP], Baviaanskloof [BK], Papkuilsfontein[PKF]) experience more summer rainfall, with a greater presence of succulents and some $C_{4}$ grasses on nearby finer grained substrates (Mucina and Rutherford, 2006). Several middens (SWP1-3) are present at Seweweekspoort, each with different aspects and altitudes within the rock faces of the Seweweekspoort valley (Chase et al., 2013). Here, three separate sets of faecal pellet samples were collected in association with the middens SWP-1, SWP-2 and SWP-3 (Figure 3a). 1) SWP-1 is surrounded by a mosaic of environments, ranging from exposed north-facing rocky slabs to a more sheltered and densely vegetated drainage line, 2) SWP-2 occupies an exposed cliff with shallow soils and low water retention potential, 3) SWP-3 is located at the valley bottom, in an area of relatively high water availability and limited potential evapotranspiration. Similarly, the two middens at Baviaanskloof (BK1 and BK2) are located either side of the NW/SE orientated Baviaanskloof valley, 


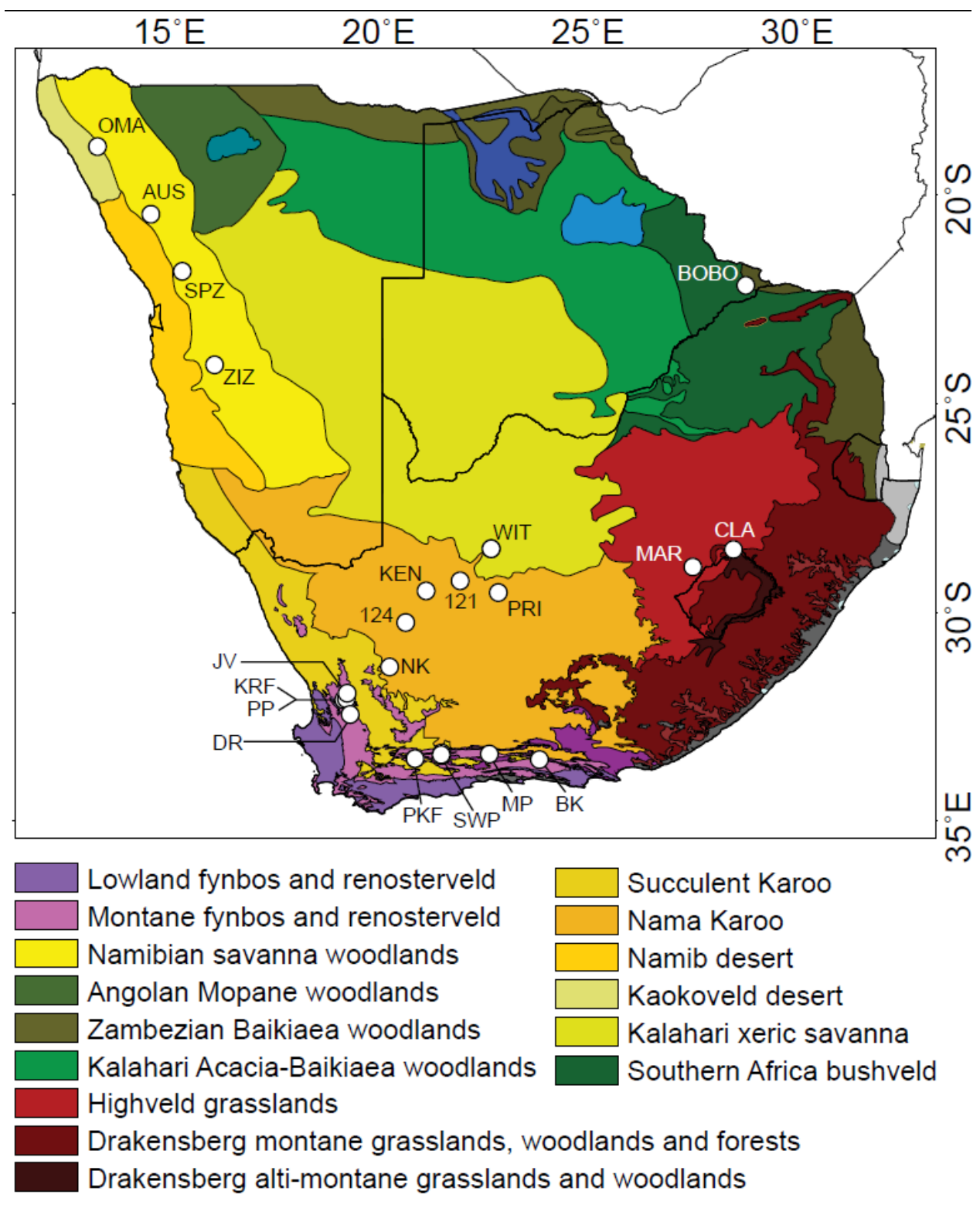

129 Figure 1: Study locations with associated vegetation communities (from Mucina and Rutherford, 130 2006). Site Key: $A U S=$ Austerlitz; $B K=$ Baviaanskloof; Bobo = Bobonong; $C L A=$ Clarens; $D R=$ De Rif; JV 131 = Jaagvlakte; KEN = Kenhardt; KRF = Kliprandfontein; $\mathrm{MAR}=$ Marikabi; $\mathrm{MP}=$ Meiringspoort; NK = 132 NK2010 (see also Carr et al., 2013); OMA = Omanyne; PP= Pakhuis Pass; PKF = Papkuilsfontein; PRI = 133 Prieska; SPZ=Spitzkoppe; SWP = Seweweekspoort; WIT = Witsand; ZIZ = Zizou. 121 and 124 = sites Mk 121 and Mk 124 (un-named Nama Karoo koppies). 
None of the Nama Karoo sites were associated with midden accumulations, but they hosted extant hyrax colonies and their inclusion provided an opportunity to expand the range of environmental conditions considered within the study. These sites, which are located at the western margins of the summer rainfall zone, include a significant proportion of $\mathrm{C}_{4}$ grasses (particularly Stipagrostis sp.). Nama Karoo vegetation in general displays a diversity of plant growth forms, and includes a range of annuals, geophytes and succulents (Mucina and Rutherford, 2006). With the exception of the Prieska site (PRI: a rocky gorge) all of the Nama Karoo sample sites were associated with isolated rock outcrops (koppies). Samples from the Savanna Biome cover a wide geographical range, from eastern Botswana (Bobonong; Bobo), to northern and central Namibia (Austerlitz, Spitzkoppe, Zizou and Omanyne [coded AUS, SPZ, ZIZ and OMA respectively]) and into the Northern

147 Cape of South Africa (Witsand; WIT) (Figure 1). The most arid locale of these sites is Omanyne in the 148 Kaokoveld desert. The Grassland Biome is represented by the Marakabi site (MAR) to the west of 149 Clocolan in the Free State (associated with an unpublished midden record) and by the Clarens site 150 (CLA), which is close to several middens described by Scott (1990). The Grassland Biome, associated with the Highveld and Drakensberg highlands can be distinguished from savanna by the strong structural dominance of grasses and notably by much cooler winter temperatures (Mucina and 153 Rutherford, 2006). The Clarens locale did not preserve middens, but the faecal pellet samples (CLA1154 CLA3) were acquired from closely located accumulations (several hundred metres apart) in an extensive north-facing escarpment $3 \mathrm{~km}$ north of the town of Clarens. The samples from Marikabi (MAR) were associated with a large midden in a rockshelter near to the top of a steep rock face. Here several separate bags of pellets were collected from accumulations within the (30-40 m across) rockshelter. Several of these sites, namely De Rif (DR - Fynbos), Seweweekspoort (SWP - Fynbos), Pakhuis Pass (PP - Fynbos), Spitzkoppe (SPZ - Savanna) and Austerlitz (AUS - Savanna) are associated hyrax middens for which there is additional published information (Chase et al., 2009, 2010, 2011, 2013, 2015b; Scott and Woodbourne, 2007a; 2007b). 

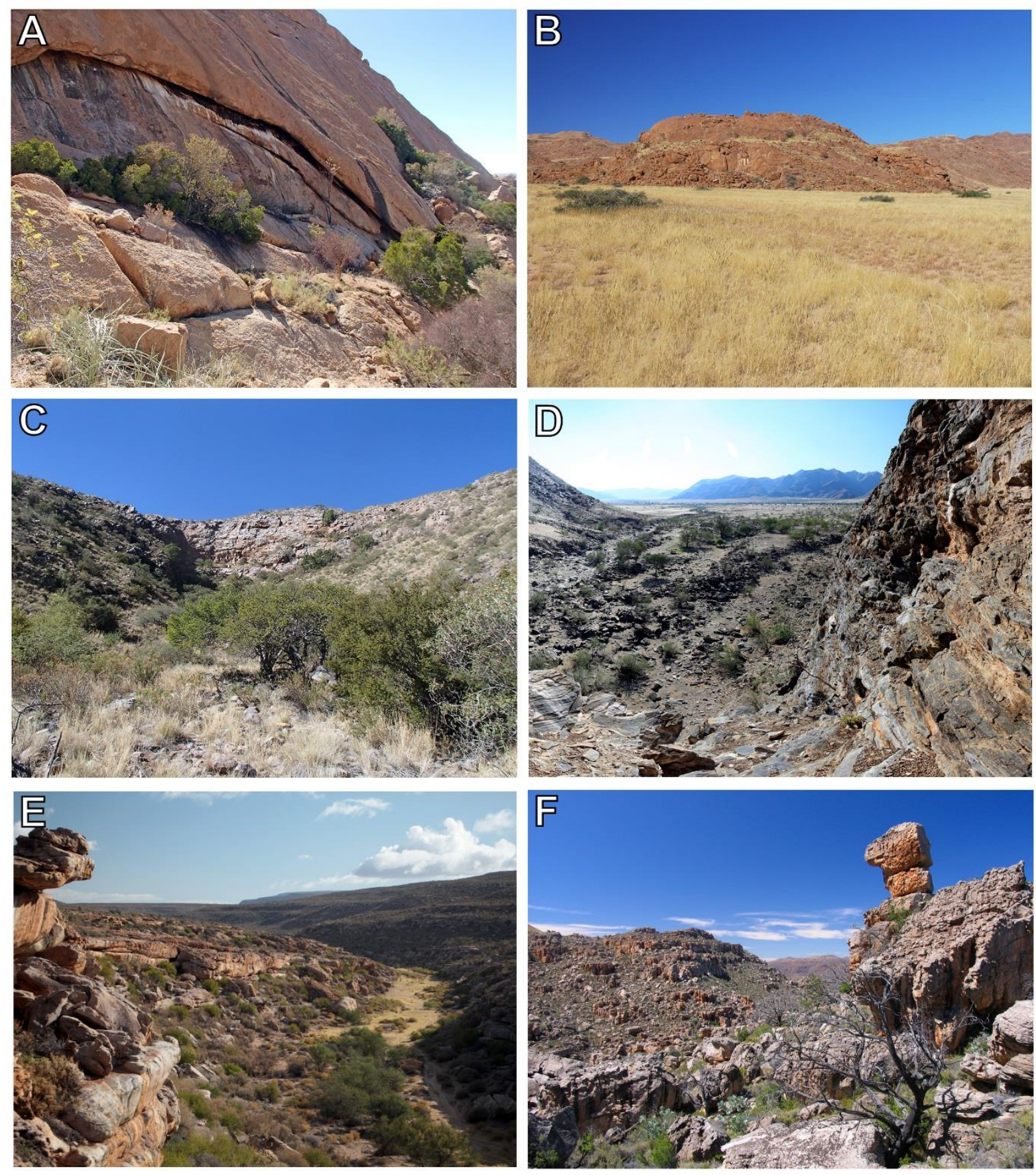

Figure 2: Photo montage of midden sites A) Spitzkoppe (SPZ, Savanna Biome) showing the upper slope below SPZ1-2, SPZ1-3 and SPZ1-5 (Chase et al., 2009) midden; B) Zizou (ZIZ, Savanna Biome; note white hyraceum staining of the rocks in the centre of the image); C) Witsand (Wit, Savanna Biome; note shading in the lower left of the valley; D) Omanyne (OMA, Savanna Biome; view down slope from immediately below the midden; E) The landscape around Jaakvlakte (JV) - the midden is located in the rocky valley sides; F) De Rif (DR) and the associated montane fynbos of the Cederberg Mountains. 
As well as assessing geographic-climatic trends in faecal $\delta^{13} \mathrm{C}$ and $\delta^{15} \mathrm{~N}$, we also sought to address how much isotopic variability is generated by individual feeding behaviour and how much inter-plant (dietary) isotopic variability exists at some sites. Food source (foliar) $\delta^{15} \mathrm{~N}$ variability will probably reflect the impact of species effects and micro-scale variability in hydrological and edaphic conditions on the rocky slopes occupied by hyraxes, but this variability remains un-quantified. To address this at several savanna sites, viz. Spitzkoppe (2013 and 2014), Omanyne (2014) and Zizou (2014), faecal pellets and plants were intensively sampled around the middens and on surrounding rock slopes. At Spitzkoppe, it was possible to sample multiple small piles of pellets, which might reflect recent feeding by one or a small number of individuals (typically 10-15 individual pellets). These were sampled systematically down-slope from the midden to the surrounding savanna plains (Figure 2). Additionally, several sites were sampled in multiple years; namely Pakhuis Pass (PP; Fynbos), Spitzkoppe (SPZ; Savanna) and Omanyne (OMA; Savanna) (Figure 1; Table 1). We sought fresh looking pellets occupying exposed rock surfaces that were unlikely to have remained undisturbed for any length of time (e.g. it is unlikely that pellets persist in exposed locations through the rainy season), but given how quickly the pellets dry out in these environments the true degree of "freshness" was difficult to assess.

Plant sampling was carried out at seven sites. Four of those sites (De Rif, Pakhuis, Jaagvlakte and NK2010) lie close to middens or hyrax colonies, but were originally sampled as part of a separate study concerning plant and soil geochemistry (see Carr et al., 2013 and 2014 for details). At these sites, plants were obtained from $10 \times 10 \mathrm{~m}$ vegetation survey plots and one representative specimen of every plant species was sampled. At Zizou, Spitzkoppe and Omanyne in the savanna biome plant sampling in 2013 and 2014 was specifically concerned with an assessment of hyrax dietary variability. Here samples were obtained from numerous individual plants (regardless of repeat sampling of the same species) within a $100 \mathrm{~m}$ radius of the midden. This included plants on the rocky slopes near the midden and some plants on the surrounding plains. It is recognised that these sampling approaches are different and that this may impact the comparability, but this issue is offset by the greater geographic/environment range afforded by the combination of data from these sites and the general paucity of foliar $\delta^{15} \mathrm{~N}$ data in South Africa and Namibia (cf. Heaton, 1987). All plant samples were air dried in the field, stored in paper bags and freeze dried in the UK.

201 Freeze-dried individual pellets, or mixtures of leaves from the same plant specimen were 202 homogenised, sub-sampled and encapsulated in tin cups. Each pellet and leaf mixture was measured 
in triplicate. Total carbon (TC), Total nitrogen (TN) and $\delta^{13} C_{T C}$ and $\delta^{15} \mathrm{~N}_{T N}$ were determined using a SerCon ANCA GSL elemental analyser interfaced to a SerCon Hydra 20-20 continuous flow isotope ratio mass spectrometer. Typical measurement reproducibility was better than $\pm 0.1 \%$ ofor $\delta^{13} \mathrm{C}$ and $\pm 0.2 \%$ for $\delta^{15} \mathrm{~N}$. Climatic data were obtained from WorldClim 1.4 (Hijmans et al., 2005), with site aridity indices derived following Trabucco and Zomer (2009). Statistical analyses were performed using Prism 6 and SigmaPlot.

\section{Results}

\section{Faecal $\mathrm{C}$ and $\mathrm{N}$ content}

The total carbon and nitrogen contents of hyrax faecal pellets are broadly consistent across the biomes (Figures S1 and S2). Faecal N content is typically 2-3\%, although several savanna sites such as Austerlitz (average $3.5 \pm 0.9 \%$ ) and Zizou, as well as NK2010 in the Nama Karoo (averages $1.4 \pm 0.6 \%$ and $1.5 \pm 0.3 \%$ respectively) show some deviation from this. $\mathrm{C} / \mathrm{N}$ ratios similarly show limited variability (typically 15-30), although some individual sites such as Zizou (33 \pm 11 ) differ markedly in comparison to other sites in the same (savanna) biome (e.g. Austerlitz; $14 \pm 4$ ). For sites sampled in multiple years (Omanyne 2008/2014, Spitzkoppe 2013/2014 and Pakhuis Pass 2008/2013) interannual differences in faecal $\mathrm{N}$ and $\mathrm{C} / \mathrm{N}$ ratios are observed (Table S1; Figure S1). Inter-annual differences in faecal $\mathrm{N}$ content are statistically significant at Omanyne and Spitzkoppe (Mann-Whitney $U=194.5, p<0.0001$ and Mann-Whitney $U=362, p<0.0001$, respectively) and less for the 2008/2013 samples Pakhuis Pass (Mann-Whitney $U=41.5, p=0.016$ ) (Table S1).

\section{Stable carbon isotopes}

\section{Fynbos Biome}

Faecal $\delta^{13} \mathrm{C}$ data from all sites in the western Fynbos Biome (i.e. PP, KRF and DR) is typically -26 to $28 \%$ and the results from these sites are statistically indistinguishable. This contrasts with the eastern Fynbos Biome sites (BK1, BK2, MP1, PKF and SWP), which show greater intra- (MP, SWP) and intersite variation (Figure 3). The BK1 and BK2 $\delta^{13} \mathrm{C}$ data are comparable $(-25.2 \pm 0.7 \%$ and $-25.8 \pm 1.2 \%$ ), with BK2 (shaded) marginally lower (the difference is not statistically significant). In terms of temporal variation, the 2008 data from Pakhuis Pass are indistinguishable from the 2013 data (means: $-26.1 \pm$ $0.4 \%$ ond $-26.4 \pm 0.4 \%$ o, $n=15$ and $n=12$, respectively). Overall, with the exception of SWP-2, faecal $\delta^{13} \mathrm{C}$ for all fynbos sites is in the anticipated range of pure $C_{3}$ plant diets. Jaakvlakte (JV)within the 
Fynbos biome $-26.5 \pm 2.0 \%(n=171)$

Savanna biome $-23.3 \pm 3.0 \%(n=327)$
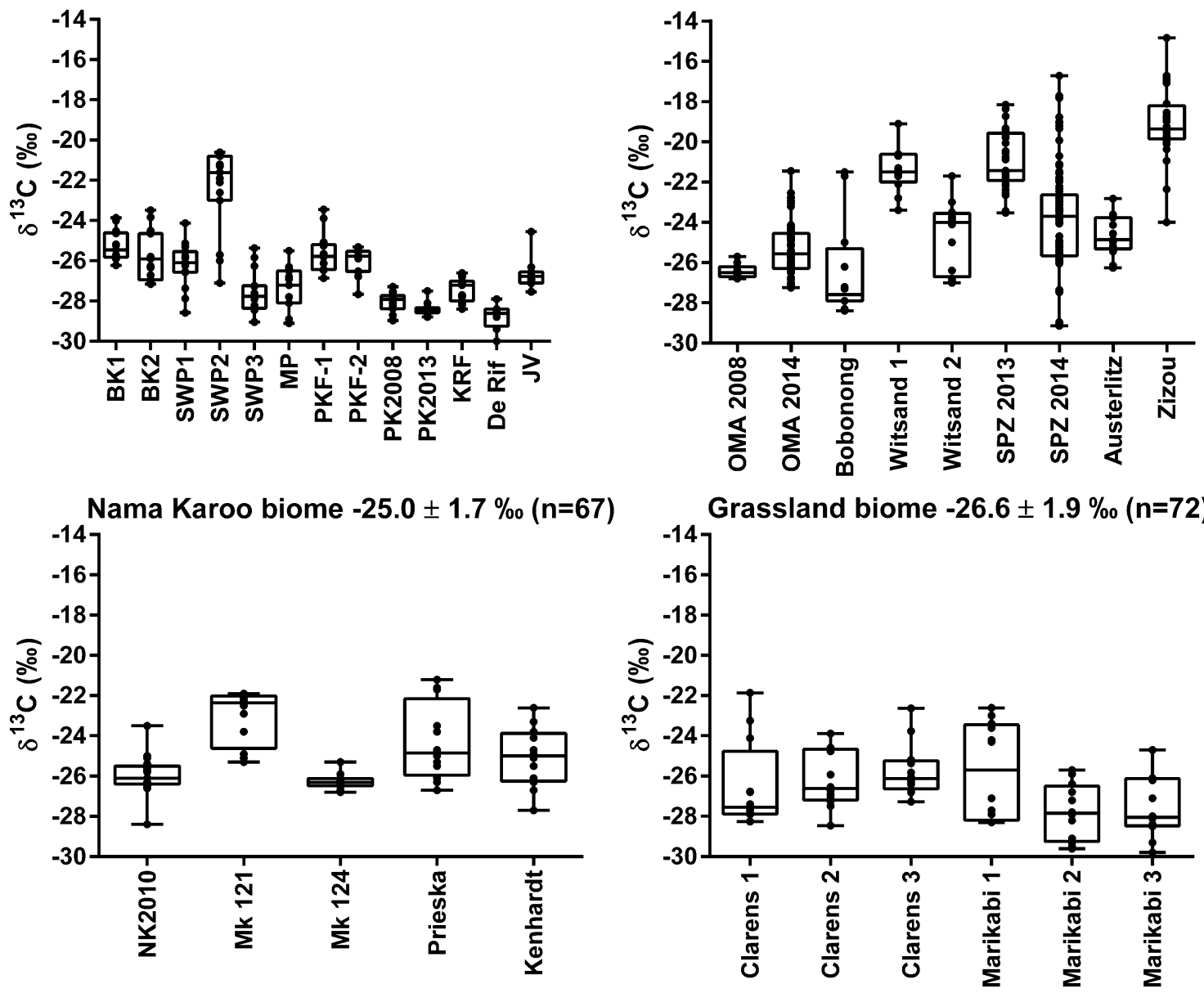

235

Figure 3: Box and whisker plots for faecal $\delta^{13} \mathrm{C}$. Plots show inter-quartile range, maximum and minimum values and all data points. For convenience the site JV (Jaagvlakte) has been plotted with sites from the (geographically close) Fynbos biome, although this specific site is actually located in the Succulent Karoo biome.

Nama Karoo Biome

242 Average faecal $\delta^{13} \mathrm{C}$ in the Nama Karoo biome $(-25.0 \pm 1.7 \%)$ is higher than the Fynbos Biome and

243 intra-site variability in the Nama Karoo is also somewhat higher than that of the Fynbos Biome, with

244 individual pellets at some sites reaching $\delta^{13} \mathrm{C}$ values of $-22 \%$. In general $\delta^{13} \mathrm{C}$ is however rather invariant across the five sites (Figure 3b) with the exception of the tightly clustered data at Mk-124. 
247 Given the significance of middens as palaeoenvironmental arhives for the savannas of central and northern Namibia (Chase et al., 2010; Chase et al., 2009; Gil-Romera et al., 2006; Gil-Romera et al., 2007; Scott, 1996; Scott et al., 2004) this region was studied in some detail. Overall, like the Nama Karoo, $\delta^{13} \mathrm{C}$ is often (e.g. Omanyne, Bobonong, Austerlitz; Figure $3 \mathrm{c}$ ) within the range anticipated for pure $C_{3}$ vegetation. However, the contribution of $C_{4}$ vegetation to the animal's diet is readily apparent at several savanna sites, both from the isotope data (in terms of both average values and inter/inter site variability) (Figure 3c) and from observations of grazed grasses at sites such as Spitzkoppe and Zizou.

Spitzkoppe (Figure 2a), Omanyne (Figure 2d) and Zizou (Figure $\mathbf{2 b}$ ) were the most intensively sampled sites. The highest site average faecal $\delta^{13} \mathrm{C}$ is seen at Zizou $(2014 ;-19.5 \pm 0.5 \%, \mathrm{n}=48)$ and the spread of pellet $\delta^{13} \mathrm{C}$ is quite broad. At Spitzkoppe, 36 pellets from three different accumulations sampled in 2013 (average $-20.9 \pm 1.5 \%$ ) and 96 pellets from 12 piles in sampled 2014 (average -23.7 $\pm 2.6 \%$ ) were analysed. The inter-annual $\delta^{13} \mathrm{C}$ difference is significant (Mann-Whitney $U=551$, two tailed $p<0.0001$ ), although it should be noted that the 2014 samples were deliberately sampled to capture potential variability at a single site (Figure 3c), whereas the 2013 samples were all collected from accumulations close to the midden itself. Relative to other savanna sites, faecal $\delta^{13} \mathrm{C}$ at Omanyne is relatively low in both 2008 and 2014, averaging $-26.4 \pm 0.4 \%$ o $(n=15)$ and $-25.3 \pm 1.3 \%$ o $(n=81)$ respectively. The difference between the two years is statistically significant (Mann-Whitney $\mathrm{U}=214$ two tailed $p<0.0001)$. Witsand (WIT), which is located in an embayment in a rocky west-facing escarpment provides a useful demonstration of micro-climatic effects (cf. Chase et al., 2013) in that there are clear differences (Mann-Whitney, $U=4.5$ two tailed $p<0.0001$ ) between the cliff top (exposed; $-21.4 \pm 1.1 \% \circ \mathrm{n}=12$ ) and cliff-bottom (shaded; $-24.7 \pm 1.7 \% \circ \mathrm{n}=12$ ) pellet accumulations (Figure 2C).

\section{Grassland Biome}

At the Clarens (CLA) site there is no significant difference in $\delta^{13} \mathrm{C}$ between the three sampled pellet accumulations (Kruskal-Wallace Test Stat 4.22, $p=0.12$ ) and the site average for all pellets is $-26.1 \pm$ 1.7\%o; $n=36$; Figure 3d). At Marikabi the average $\delta^{13} \mathrm{C}$ for the three collections of pellets ranges from $-25.7 \pm 2.3 \%$ o ( $n=12)$ to $-27.8 \%$ $\pm 1.4 \%$ o $(n=12)$, but as at Clarens, there is no significant difference in $\delta^{13} \mathrm{C}$ between the faecal pellet collections (Krsukal-Wallace Test Stat $=4.92, p=0.09$ ). Overall, the data suggest a $C_{3}$ diet, although there is more scatter in $\delta^{13} \mathrm{C}$ for the Grassland Biome than the Fynbos Biome (Figure 3d), perhaps suggesting a more diverse diet or range of plant foliar $\delta^{13} \mathrm{C}$. 
Foliar $\delta^{13} \mathrm{C}$

Plant samples were obtained for seven sites in the Fynbos, Succulent Karoo, Nama Karoo and Savanna biomes (Table 1; Figure 4). Here we focus on the analysis of foliar material, although we recognise that other plant parts may be consumed by hyraxes, and such data will be presented elsewhere. Plants from the Cederberg in the western Fynbos Biome were obtained from De Rif (DR) and Pakhuis Pass (PP). Foliar $\delta^{13} \mathrm{C}$ at De Rif is higher and exhibits a wider range $(-26.3 \pm 2.3 \% \mathrm{n}=7)$ than faecal $\delta^{13} \mathrm{C}(-$ $28.8 \pm 0.7 \% \circ n=12$ ), a pattern repeated at Pakhuis Pass (foliar average $-27.0 \pm 0.7 \% \circ n=6$; faecal average $-28.2 \pm 0.5 \% \circ \mathrm{n}=27$ ) and Jaagvlakte (JV; foliar average $-26.0 \pm 2.7 \% \circ \mathrm{n}=8$; faecal average $26.7 \pm 0.7 \%$ o $=15$ ). Plants in the Nama Karoo and Savanna biomes exhibit bimodal foliar $\delta^{13} \mathrm{C}$ distributions, reflecting their mixed $C_{3} / C_{4}$ vegetation communities. As anticipated, at NK2010 all sampled grasses utilised the $C_{4}$ photosynthetic pathway (average $\delta^{13} \mathrm{C}-14.0 \pm 0.7 \%$ on $=4$ ). The resulting site average foliar $\delta^{13} \mathrm{C}$ is thus associated with a large standard deviation $(-23.0 \pm 6.3 \% \mathrm{n}=$ 14 ), reflecting this mixture of photosynthetic pathways. Faecal $\delta^{13} \mathrm{C}$ is lower (average $-25.9 \pm 0.6 \% \mathrm{n}$ $=19$ ) and less scattered than the foliar data. It is only slightly higher than the mean foliar $\delta^{13} \mathrm{C}$ of the non- $\left(C_{4}\right)$ grasses $(-26.7 \pm 2.5 \% \circ n=10)$ implying a minor $C_{4}$ contribution to diet.
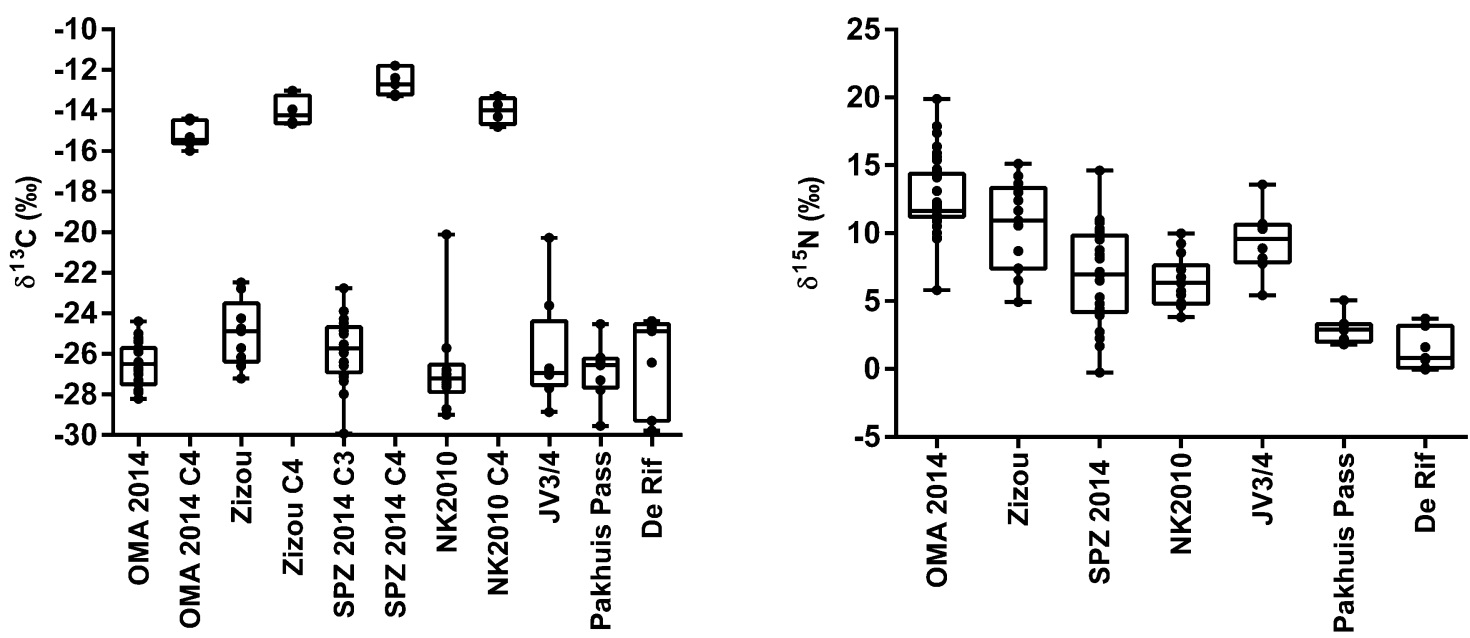

293

Figure 4: Foliar $\delta^{13} \mathrm{C}$ and $\delta^{15} \mathrm{~N}$ data. Plots show inter-quartile range with maximum and minimum values. For clarity $C_{4}$ specimens are plotted separately from $C_{3}$ plants for sites in the savanna and Nama Karoo biomes. In the Savanna Biome, 36 plants from Omanyne (OMA) were collected within $100 \mathrm{~m}$ of the midden. The site average foliar $\delta^{13} \mathrm{C}$ is $-23.4 \pm 5.2 \%$, but the distribution is strongly bimodal reflecting the sampling of ten $\mathrm{C}_{4}$ grasses (Figure 4; average $-15.2 \pm 0.6 \%$ ) and $26 \mathrm{C}_{3}$ shrubs and trees $(-26.6 \pm 1.1 \%$ ). 
301

302

303

304

305

306

307

308

309

310

311

312

313

314

315

316

317

318

319

320

321

322

323

324

325

At Zizou (ZIZ) the average shrub/tree foliar $\delta^{13} C$ is $-25.0 \pm 1.6 \%$ o $(n=9)$, while three $C_{4}$ grass specimens growing on the outcrop hosting the midden and on the flat grassy plain below (Figure 2) produce an average $\delta^{13} \mathrm{C}$ of $-14.4 \pm 0.1 \%$ o $(n=3)$. The site average faecal $\delta^{13} \mathrm{C}$ at ZIZ $(-19.0 \pm 1.6 \% \circ \mathrm{n}=48)$ therefore implies a contribution of $\mathrm{C}_{4}$ grasses to the diet, consistent with observational evidence for grazing (Figure 2). 27 plants at Spitzkoppe (SPZ) were sampled across the rocky slopes below the midden (Figure 2) and these comprised a diverse mix of shrubs (Asteraceae), trees (Ficus illcina, Rhus sp., and Olea sp.), succulents (Sarcostema viminale) and grasses. In several locations the latter had been grazed upon. A specimen of the stem succulent Sarcostema viminale demonstrated the presence of CAM plants $(-13.2 \%$; $n=1)$, while all sampled grasses were $C_{4}(-12.5 \pm 0.6 \% n=6)$. The foliar average $\delta^{13} C$ for the SPZ $C_{3}$ shrubs and trees (excluding the CAM specimen) was $-25.8 \pm 1.6 \%$ o $(n=20)$. The faecal $\delta^{13} \mathrm{C}$ (Figure 3) therefore suggest that grasses/CAM form some part of the hyrax diet at this site, but there is a broad spread, particularly for the 2014 samples (average $-23.7 \pm 2.6 \%$, range -29.1 to $16.7 \%$ ).

\section{Stable nitrogen isotopes}

\section{Fynbos Biome}

There is considerable variability in faecal $\delta^{15} \mathrm{~N}$ for the Fynbos Biome (Figure 5a). The site averages range from $13.4 \pm 1.1 \%$ o (KRF) to $0.7 \pm 1.2 \%$ o (SWP-3) with maximum and minimum individual pellet values of $18.5 \%$ (BK1) and $-3.3 \%$ (SWP-3). Despite its outlier position for $\delta^{13} \mathrm{C}$, SWP-2 produced an average $\delta^{15} \mathrm{~N}$ close to SWP-1 and SWP-3. The presence of one or two outliers within otherwise tightly clustered datasets (e.g. BK1, KRF, SWP-3; Figure 5a) is a noteworthy feature in the Fynbos faecal $\delta^{15} \mathrm{~N}$ data; something less apparent in other biomes (Figure 5) and the $\delta^{13} \mathrm{C}$ data (Figure 3). As with $\delta^{13} \mathrm{C}$, repeat sampling in 2008 and 2013 at Pakhuis Pass (PP) produced indistinguishable results $(8.1 \pm 0.7 \%$ o $(n=15)$ and $8.3 \pm 1.0 \%$ o $(n=12))$. In the Succulent Karoo, the highest site average faecal $\delta^{15} \mathrm{~N}$ of any site in the study is observed at Jaagvlakte (JV; $15.5 \pm 2.3 \% \circ n=15$ ). 
Fynbos biome $7.1 \pm 4.4 \%$ ( $n=171)$

Savanna biome $10.8 \pm 2.7 \%$ o $(n=329)$
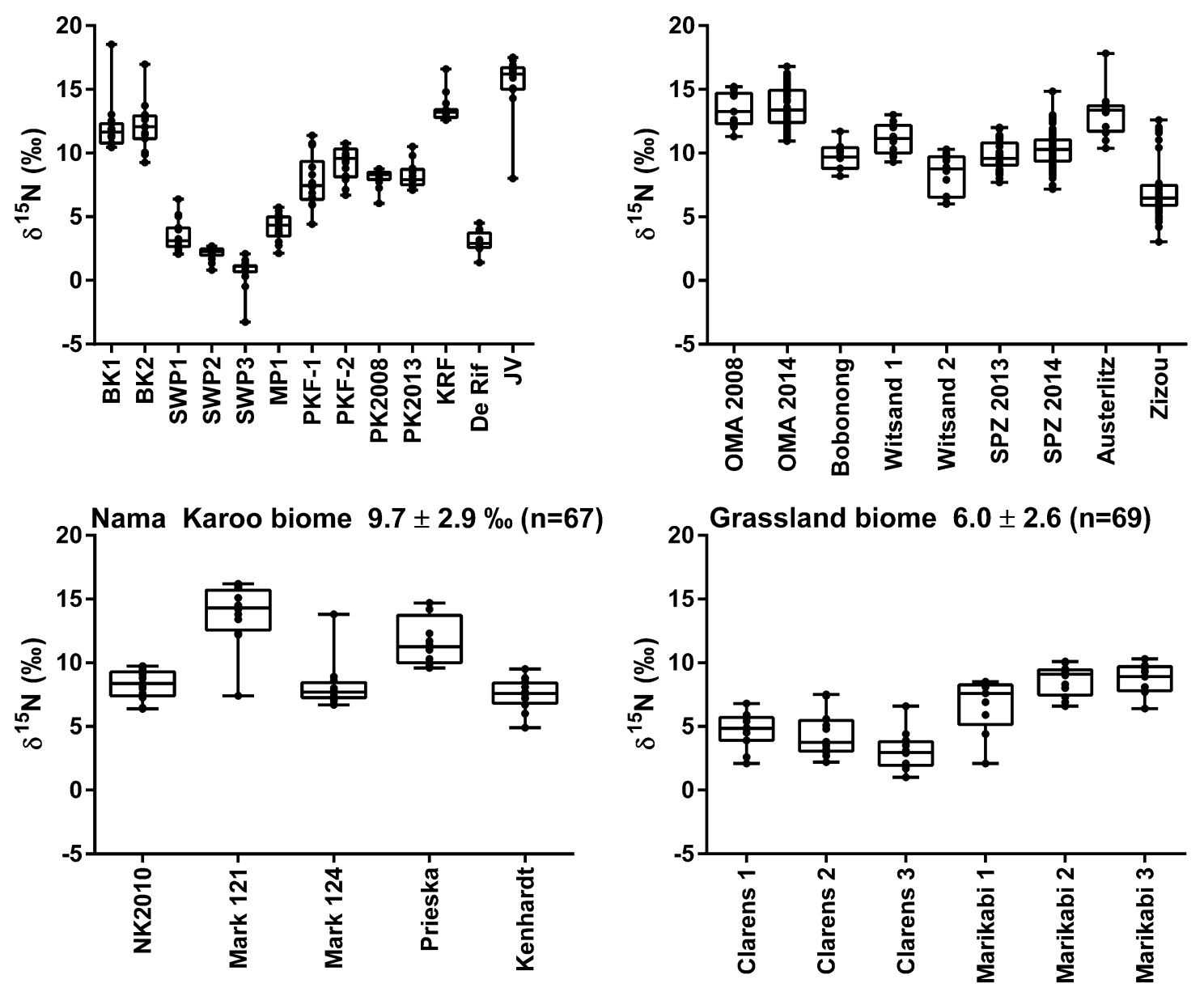

Figure 5: Box and whisker plots for faecal $\delta^{15} \mathrm{~N}$. Plots show inter-quartile range with maximum and minimum values. For convenience the site JV (Jaagvlakte) has been plotted with sites from the (geographically close) Fynbos biome, although this specific site is itself located in the Succulent Karoo

\section{Nama Karoo Biome}

Faecal $\delta^{15} \mathrm{~N}$ is higher in the Nama Karoo than in the Fynbos Biome (biome average $9.7 \pm 2.9 \%$ ) and there is markedly less inter-site variability (Figure 5). Some intra-site variability is apparent, but in the case of Mk121 and Mk124 this is influenced by individual outlier pellet values.

\section{Savanna Biome}

In the savanna site average $\delta^{15} \mathrm{~N}$ (Figure 5c) ranges from $13.6 \pm 1.6 \%$ (Omanyne 2014, $\mathrm{n}=81$ ) to $7.1 \pm$ 2.2\%o (Zizou $n=48$ ). The 2008 and 2014 data for Omanyne are identical ( $13.5 \pm 1.4 \% n=15$ and $13.6 \pm$ $1.6 \%$ $n=81$ respectively). The 2013 and 2014 data from Spitzkoppe differ slightly $(9.7 \pm 1.1 \% \circ n=41$ and $10.3 \pm 1.3 \% \mathrm{n}=96$ respectively) and this difference is statistically significant (Mann-Whitney $U$ $=1457$ two tailed $p=0.016$ ). The data from Zizou show a bimodal faecal $\delta^{15} \mathrm{~N}$ distribution (modes of $6.2 \pm 0.1 \% \circ n=40$ and $11.6 \pm 0.7 \% \circ n=8$; Figure 6). The majority of faecal pellets are associated with 
the lower mode. The higher $\delta^{15} \mathrm{~N}$ mode is associated with a higher faecal $\mathrm{N}$ content $(\% \mathrm{~N}$ average of $2.5 \pm 0.9 \%$ compared to $1.1 \pm 0.2 \%$ ) but $\delta^{13} \mathrm{C}$ values (-19.6\%) comparable to the lower mode. As with $\delta^{13} \mathrm{C}$, the upper and lower sites from Witsand show a statistically significant difference (Mann-Whitney $U=10.5$, two tailed $p<0.001$ ), with the more exposed cliff top site averaging of $11.2 \pm 1.2 \%$ and the lower site $8.3 \pm 1.6 \%$.

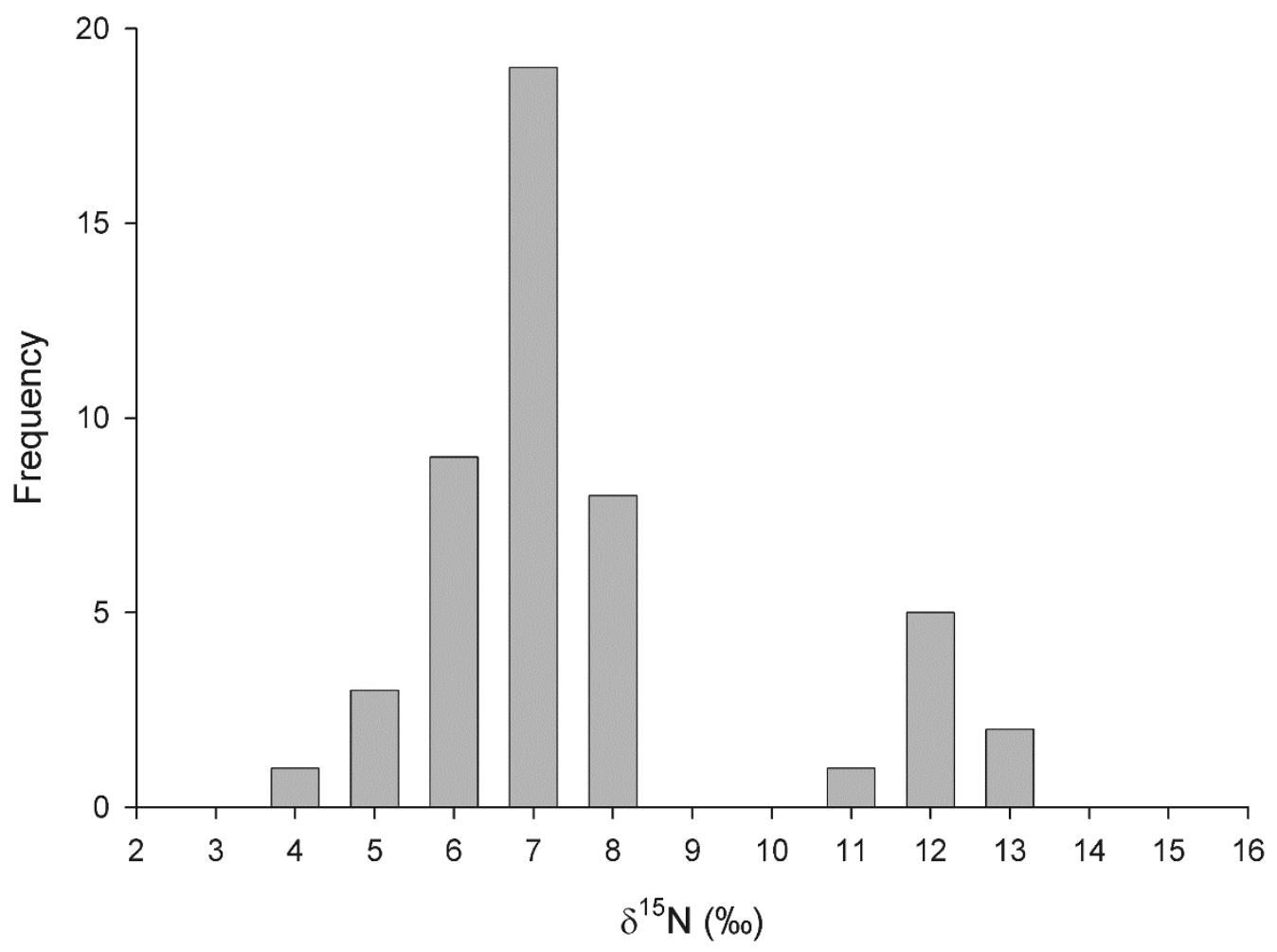

Figure 6: Zizou faecal pellet $\delta^{15} \mathrm{~N}$ distribution

\section{Grassland Biome}

351 The Grassland Biome (Figure 5d) shows a clear distinction between the Marikabi (MAR; $6.6 \pm 2.2$ to $3528.8 \pm 1.3 \%$ ) and Clarens sites (CLA sampling averages $3.1 \pm 1.4$ to $4.7 \pm 1.4 \%$ ), although intra-site variability is comparable to other sites in the study (ranges of $2-6 \%$ ). As with $\delta^{13} \mathrm{C}$, there are no significant differences between the three pellet accumulations sampled at each site.

\section{Plant foliar $\delta^{15} \mathrm{~N}$}

356 Scatter in foliar $\delta^{15} \mathrm{~N}$ is greater than that observed in the faecal pellets (Figure 4). Site averages vary 357 from a minimum of $1.4 \pm 1.5 \%$ o $(n=7)$ at De Rif (DR; Fynbos Biome) to a maximum of $12.5 \pm 1.6 \%$ o $(n=$ 358 36) in the Savanna Biome (Omanyne). Foliar $\delta^{15} \mathrm{~N}$ at the two fynbos sites is substantially lower than 
the other biomes (DR $1.4 \pm 1.5 \% \circ n=7$; PP $2.9 \pm 1.0 \% n=8$ ). Savanna foliar $\delta^{15} N$ shows considerable variability (Figure 4). Interestingly, at Spitzkoppe, Zizou, NK2010 and Omanyne $\delta^{15} \mathrm{~N}$ tends to be lower in $\mathrm{C}_{4}$ grasses compared to the $\mathrm{C}_{3}$ plants (Table 2). The difference is most striking at Zizou (MannWhitney $\mathrm{U}=0$ Two tailed $p=0.003$; Table 2 ) although it is also statistically significant at Spitzkoppe and Zizou. Similarly, in the Nama Karoo foliar $\delta^{15} \mathrm{~N}$ at NK2010 is bimodal distributed, with the four specimens of $\mathrm{C}_{4}$ grass associated with the lower mode ( $4.5 \%$; Mann-Whitney $\mathrm{U}=8$ Two tailed $\mathrm{p}=0.03$ ). Foliar N content is also very variable (Figure S3) and in the Fynbos biome (DR and PP), foliar $\mathrm{N}$ is low compared to other biomes (Table 2). In the savanna biome foliar $\mathrm{N}$ content is also significantly lower in $C_{4}$ grasses compared $\left(C_{3}\right)$ shrubs and trees at the same site (e.g. Codron et al. 2005) (Table 2).

\section{Faecal stable isotope variability at a single site}

370 At the intensively-sampled Spitzkoppe site it was possible to observe the isotopic variability of multiple small pellet piles, which we hypothesised were deposited by a limited number of individuals during short periods of recent feeding. There are marked differences in ${ }^{13} \mathrm{C}$ and ${ }^{15} \mathrm{~N}$ content between individual pellet accumulations; some piles have tightly clustered $\delta^{13} \mathrm{C}$ and $\delta^{15} \mathrm{~N}$ while others have very broad ranges (Figure 7). Narrow $\delta^{13} \mathrm{C}$ and $\delta^{15} \mathrm{~N}$ ranges are seen at pellet piles 2, 4, 6 and 13 and imply feeding associated with a singular or restricted range of plant browse. None of these tightly clustered sites exhibit $\delta^{13} \mathrm{C}$ greater than $-23 \%$, consistent with the upper range $C_{3}$ plant foliar data $\delta^{13} \mathrm{C}$ (Figure 4). Flexibility in feeding is apparent however, as several pellet piles comprised a mix of pellets that contain largely $C_{4}$ plant-derived matter and also pellets composed largely of $C_{3}$-derived plant matter (e.g. sites 3 and 9). In some cases, the impact of the aforementioned tendency for lower $\delta^{15} \mathrm{~N}$ in $\mathrm{C}_{4}$ grasses at this site (Table 2) is also apparent (e.g. sites 3 and 7). The distance from the midden increases with site number, but there is no tendency in these data for the scatter to be greater in pellet piles further from the midden. 


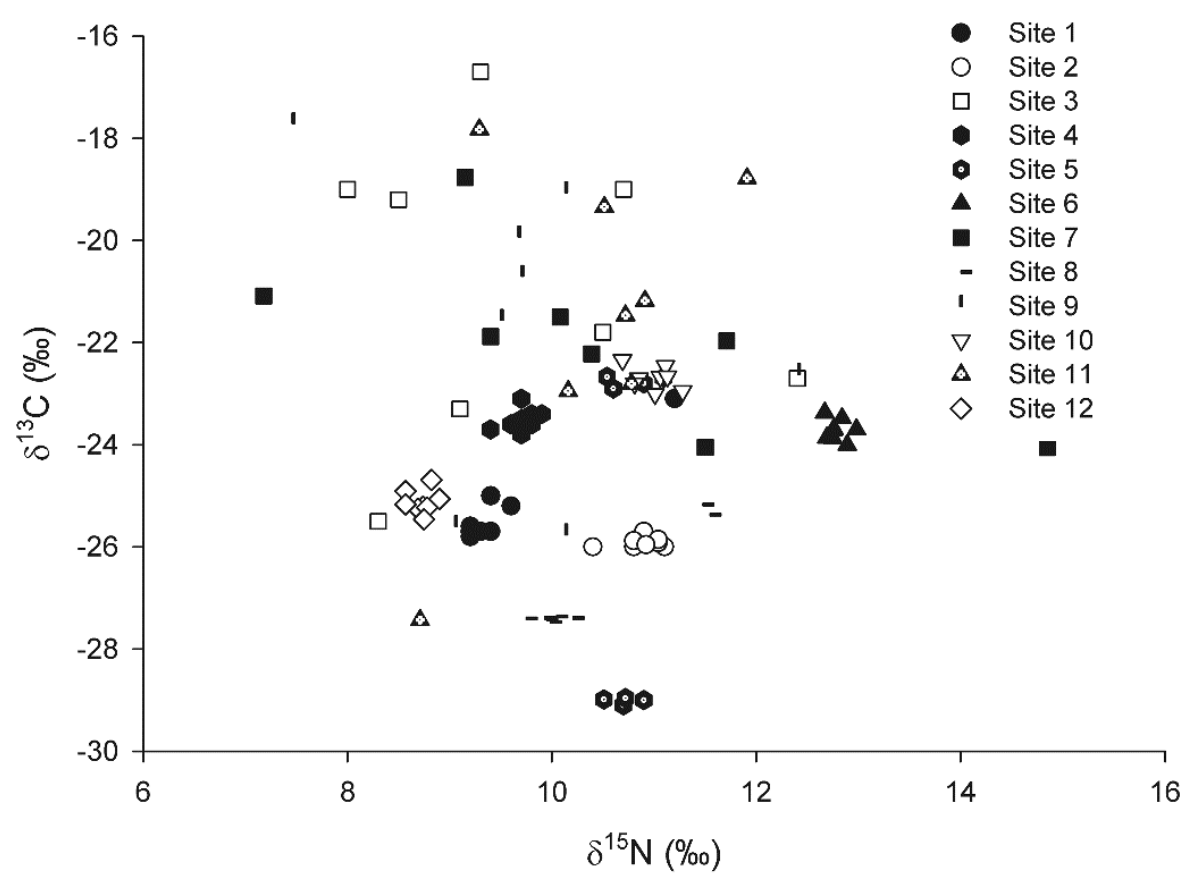

Figure 7: $\delta^{13} \mathrm{C}$ and $\delta^{15} \mathrm{~N}$ from individual pellet piles sampled down the slope from the Spitzkoppe midden. No pellet pile is indicative of focused $\mathrm{C}_{4}$ grass feeding

\section{Discussion} In this study we sought to 1 ) address dietary variability via the analysis of faecal $\delta^{13} \mathrm{C}$, and 2 ) address controls on animal tissue $\delta^{15} \mathrm{~N}$ within the hyrax ecosystem. Overall, the data demonstrate considerable variability in the stable carbon and nitrogen isotope composition of rock hyrax faecal pellets, as well as considerable intra/inter-site variability in foliar $\delta^{15} \mathrm{~N}$ and foliar $\delta^{13} \mathrm{C}$.

\section{$392 \quad$ Faecal $\delta^{13} \mathrm{C}$, grazing and browsing}

393 Faecal $\delta^{13} \mathrm{C}$ responds to anticipated variability in foliar $\delta^{13} \mathrm{C}$ across the southern African biomes (e.g. Vogel et al., 1978; Still and Powell 2010) and we observe obvious differences between the Fynbos ( $C_{3}$ vegetation), Succulent Karoo ( $C_{3} /$ CAM vegetation) and the Savanna / Nama Karoo Biomes, in terms of both average faecal $\delta^{13} \mathrm{C}$ and faecal $\delta^{13} \mathrm{C}$ range. Faecal $\delta^{13} \mathrm{C}$ has been shown to effectively characterise the feeding behaviour of herbivores (Ambrose, 1986; Tieszen et al., 1979). Proposed faecal $\delta^{13} C$ for $C_{3}$ browsers, $C_{4}$ grazers and mixed feeders are $-26.3 \pm 1.0 \%$ o, $-14.3 \pm 1.2 \%$ ond $-19.6 \pm 3.7 \%$ o, respectively (Codron and Codron, 2009). These ranges are plotted with our data in Figure 8, from which we infer dominantly browsing behaviour. Only $10 \%$ of the 653 pellets analysed had measured $\delta^{13} \mathrm{C}$ values $\geq 19$ \%. In the Fynbos, as anticipated, faecel $\delta^{13} \mathrm{C}$ implies a $\mathrm{C}_{3}$ diet. We find do not find evidence for the 
substantial consumption of CAM plants within the Fynbos, with the possible exception of SWP-2, which accounts for every data point higher than $-24 \%$ in the Fynbos biome (Figure 8a). This may reflect the shallow soils surrounding the site and the occurrence of associated succulent plants at this locale. Rock hyraxes have been observed to feed on CAM plants (several species of $A / o e$ ) in the Eastern Cape Province, but this represented a minor contribution to diet and was restricted to drier months 407 of the year (Fourie, 1983). In the other biomes faecal $\delta^{13} \mathrm{C}$ values of between -23 and $-16 \%$ o suggest mixed-feeding, most obviously in the Savanna (e.g. Figure 7). In the Grassland Biome, the generally low faecal $\delta^{13} \mathrm{C}$ for Clarens and Marikabi are consistent with prior observations in this region that implied limited grass consumption (Scott and Vogel, 2000). This was thought to reflect the unpalatable nature of "sour grass" in this region and cooler conditions relative to the rest of the summer rainfall zone (ibid).
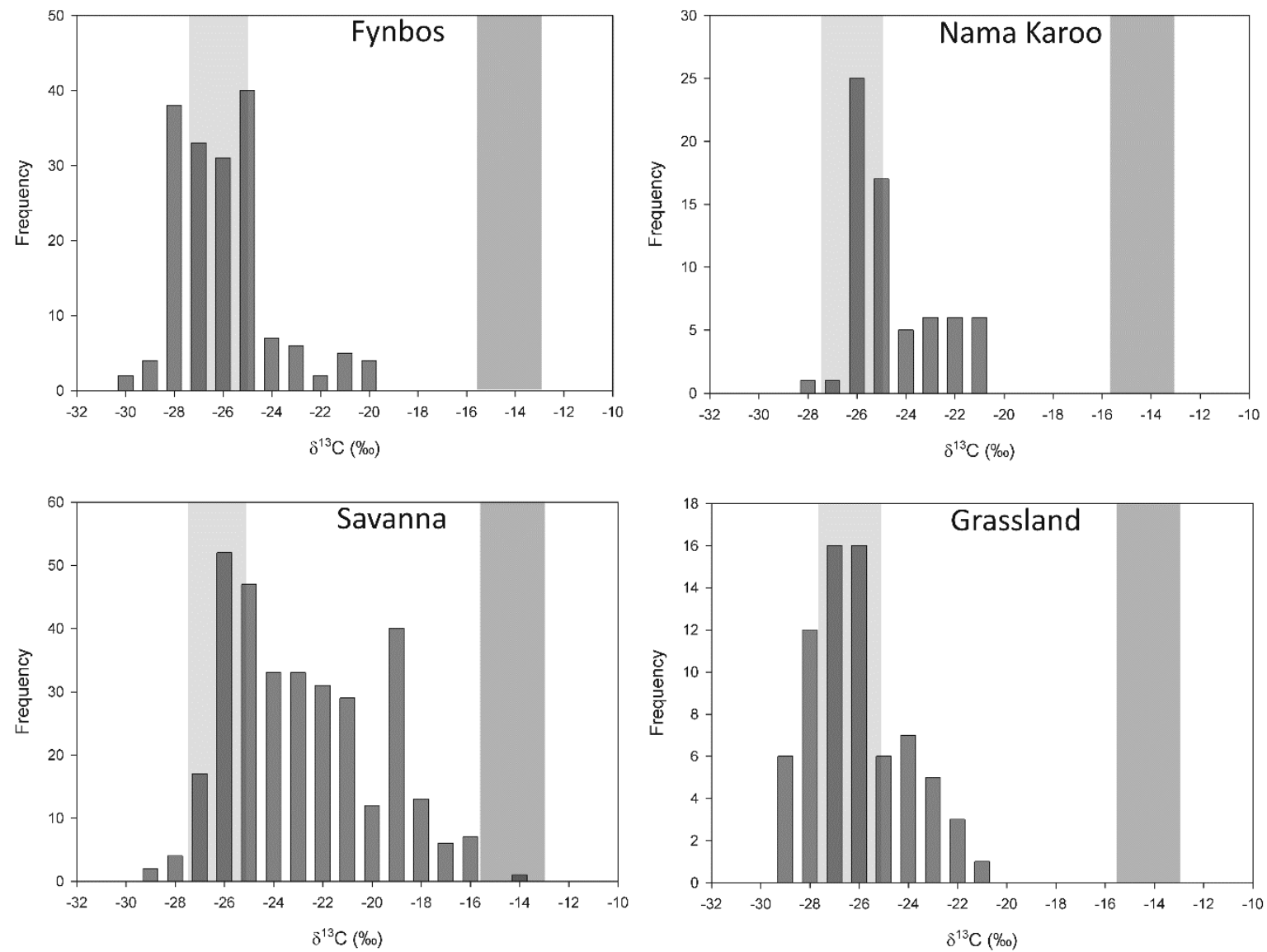

413

Figure 8: All measured pellet $\delta^{13} \mathrm{C}$ presented by biome. Grey bands show the pure grazer (dark grey) and browser (light grey) $\delta^{13} \mathrm{C}$ ranges proposed by Codron and Codron (2009). 
For sites with foliar $\delta^{13} \mathrm{C}$ data (Table 2) the proportion of $\mathrm{C}_{3} / \mathrm{C}_{4}$ consumption can be estimated from the faecal $\delta^{13} \mathrm{C}$; after first correction for a $-0.8 \%$ offset between dietary and faecal $\delta^{13} \mathrm{C}$ 419 (Sponheimer et al. 2003a). At Omanyne, hyrax diet in 2008 and 2014 was dominated by $C_{3}$ vegetation 420 (90\% and 80\% respectively). At Zizou, the July 2014 data indicate mixed feeding, with average faecal $\delta^{13} \mathrm{C}\left(-19.0 \pm 1.6 \%\right.$ ) implying $\sim 40 \% \mathrm{C}_{3}$ plant contribution to diet. At Spitzkoppe the $\mathrm{C}_{3}$ contribution was $\sim 56 \%(n=36)$ in May 2013 and $\sim 77 \%$ in July $2014(n=96)$. At NK2010 $C_{3}$ consumption was $\sim 82 \%(n=15)$. These data therefore indicate some variability, even within the same biome (savanna). Some of this can be accounted for with consideration of the site settings. For example, at Omanyne the dominantly $\mathrm{C}_{3}$ diet probably reflects the location of the midden on a steep rocky slope dominated by shrubs and trees with few grasses within a $50 \mathrm{~m}$ feeding radius of the midden (Figure $\mathbf{2 d}$ ). By contrast, Zizou is located on a small outcrop and lies immediately adjacent to a wide grassy plain, well within the animal's feeding range (Figure $\mathbf{2 b}$ ). The more substantial contribution of grasses to diet here is therefore unsurprising and is supported by the grazed appearance of the grasses around the site. The rocky slopes at Spitzkoppe support a mixture of localised grasses, abundant shrubs and several species of tree, with a mixed diet implied by the faecal $\delta^{13} \mathrm{C}$ data. Grasses only dominate on the plains surrounding Spitzkoppe (Figure 2a), which are beyond the safe foraging distance for hyraxes occupying the rock slopes (Kotler et al., 1999). The trees also include one species (Olea europeae) previously reported to be a significant contributor to the rock hyrax diet (Fourie, 1983).

Questions of dietary preference must be considered in the context of the temporal availability of plant type, and observations of animal behaviour (e.g. Lensing, 1983; Fourie, 1983). It has, for example, been shown that the foraging range can fluctuate seasonally, depending on food availability (Brown and Downs, 2005). Lensing (1983) demonstrated that despite a diverse diet, as much as $90 \%$ of an individual's stomach contents can comprise 2-4 plant species. Fourie (1983) similarly observed that just 10 species (mostly trees and shrubs) accounted for $~ 83 \%$ of hyrax food consumption in the Eastern Cape Province of South Africa. Here we observe that the range in faecal $\delta^{13} \mathrm{C}$ is generally lower (typical standard deviations for pellet piles are $\pm 1.5 \%$ ) than foliar $\delta^{13} \mathrm{C}$ variation (typical site standard deviations are $\pm 3.0 \%$ ) .

In terms of temporal variability, while trees and shrubs may access to deeper water resources, in arid regions with seasonal and restricted growing seasons, the period of elevated protein and water content (and thus palatability) in grasses is restricted to a few weeks of the year (Grunow et al., 1970).

447 Observations of $P$. capensis behaviour and analysis of their stomach contents (Lensing, 1983; Fourie, 1983; Skinner and Chimimba, 2005) suggests that the rock hyrax is an opportunistic feeder, and that 
sprouting. This period was observed to last for a matter of weeks in Namibia (Lensing, 1983) and to end quickly as grass protein content falls in response to peak summer temperatures (Fourie, 1983). Supporting this, we note that the $\mathrm{N}$ (approximation of protein) content of grasses sampled in the savanna biome, which here were mostly sampled at the end of the wet season /early dry season (Table 1) is lower than that of the shrubs and trees at the same sites (Table 2). The role of foliar $\mathrm{N}$ content in influencing seasonal grazing and browsing has been noted for other herbivores (Botha and Stock, 2005).

Observational data suggest that while they may graze during times when fresh grasses are available (Hoeck, 1975; Sale, 1965) - and grasses can reach as much as $40-60 \%$ of food intake (see Fourie 1983) - hyraxes are required to browse in many instances, exploiting various plant species and parts, depending on conditions and their needs (Skinner and Chimimba, 2005). The isotopic and \% data here are essentially consistent with this. For example, the $2013 / 2014$ faecal $\delta^{13} C$ and $\% \mathrm{~N}$ data from Spitzkoppe imply a differences in food sources for different years (Figure 7). The differences in $C_{3} / C_{4}$ consumption for 2013 and 2014 may, to some extent, reflect our differing sampling strategies (see above), but summer in 2014 was reported to have been drier than previous years by local residents, commensurate with a greater reliance on browse and the lower faecal $\delta^{13} \mathrm{C} /$ higher $\% \mathrm{~N}$ (Figure S1). Precisely how seasonality impacts our data more generally is difficult to assess, partly because the identification of fresh pellets is challenging. Nonetheless, assuming that most samples were deposited shortly prior to sampling (within weeks), it is possible that $\mathrm{C}_{4}$ grass palatability may have been higher earlier in wet (summer) season (Lensing, 1983) (Table 1). The maximum contribution of $\mathrm{C}_{4}$ grasses may be higher than our estimates imply.

The question of whether these faecal data are mirrored in the hyraceum (hyrax midden) ${ }^{13} \mathrm{C}$ content is important. For sites hosting hyrax middens with recent (last century) midden accumulation (Table S2), we observe that faecal $\delta^{13} \mathrm{C}$ is almost always lower than hyraceum $\delta^{13} \mathrm{C}$ (average offset 1.3 $\pm 1.1 \%$ o). The relationship between these two variables across multiple site/environments is difficult to assess as most data points cluster between -25 and $-26 \%$, with the single higher value for Spitzkoppe. However, the higher faecal $\delta^{13} \mathrm{C}(-20.9 \pm 1.5 \%$ o) at Spitzkoppe is mirrored in the hyraceum $\delta^{13} \mathrm{C}$ (-20.1 $\pm 1.2 \%$; average of six samples spanning the last 120 years) (Table S2). In summary, faecal $\delta^{13} \mathrm{C}$ suggests that where a mixed $C_{3} / C_{4}$ diet is available the rock hyrax will graze, depending on seasonal grass palatability and probably, protein content, but that for much of the year they are restricted to browsing. At several sites, it is also apparent that the landscape around the hyrax colony and associated spatio-temporal variability of palatable vegetation may account for inter-site differences in the pellet isotopic signature. 


\section{Nitrogen isotopes}

While the utility of faecal $\delta^{13} \mathrm{C}$ as a means to infer diet is established, the interpretation of faecal $\delta^{15} \mathrm{~N}$ is more challenging (Codron and Codron, 2009). In this study, considerable inter-site variability in faecal $\delta^{15} \mathrm{~N}$ is observed. Faecal $\delta^{15} \mathrm{~N}$ at some sites is higher than values (albeit from different environments) for browsing and grazing African herbivores (Codron et al., 2005; Codron and Codron, 2009), but these findings are not inconsistent with previous reports of high hyrax tissue $\delta^{15} \mathrm{~N}$ (Ambrose and De Niro, 1986a; Sealy et al., 1987).

Given the range of potential environmental and physiological controls on animal tissue $\delta^{15} \mathrm{~N}$, even for herbivores fed the same diet (Sponheimer et al., 2003b; Codron et al. 2012), the interpretation of this variability is complex (e.g. Ambrose and DeNiro, 1986a; Hartman and Danin, 2010; Murphy and Bowman, 2006). A first step is to compare the faecal $\delta^{15} \mathrm{~N}$ with the food source. As might be anticipated (Hartman, 2011; Hartman and Danin, 2010; Murphy and Bowman, 2006), due to the range in soil conditions, water availability and plant types in the complex micro-topography of rock hyrax habitats there is marked scatter in foliar $\delta^{15} \mathrm{~N}$ (Figure 4; Table 3). We observe over 20\%o variation in the complete foliar $\delta^{15} \mathrm{~N}$ dataset and up to $15 \%$ in single biomes and single sites (e.g. Omanyne and Spitzkoppe). Such foliar $\delta^{15} \mathrm{~N}$ variability is not unprecedented (e.g. Craine et al., 2012). We also observe a tendency for $C_{4}$ grass $\delta^{15} \mathrm{~N}$ to be lower than $C_{3}$ shrub/tree $\delta^{15} \mathrm{~N}$ at the same site (Table 2). This difference is not significant at all sites. Inconsistent differences in foliar $\delta^{15} \mathrm{~N}$ for different photosynthetic pathways have been reported (e.g. Aranibar et al., 2008; Hartmann and Danin 2010; Murphy and Bowman, 2006), with no differences reported in some studies (Heaton, 1987).

When individual sites are considered, faecal $\delta^{15} \mathrm{~N}$ is generally higher than foliar (dietary) $\delta^{15} \mathrm{~N}$ (Table 3) (e.g. Ambrose and DeNiro, 1986; Sutoh et al., 1987; Sponheimer et al. 2003c). As observed with $\delta^{13} \mathrm{C}$, intra-site variability (i.e. standard deviations; Table 3) in faecal $\delta^{15} \mathrm{~N}$ is substantially ( $\left.50 \%\right)$ lower than foliar $\delta^{15} \mathrm{~N}$, most likely indicating selective feeding (see above) and homogenisation within the digestive tract. We observe a (non-significant) positive correlation between site average faecal $\delta^{15} \mathrm{~N}$ and site average foliar $\delta^{15} \mathrm{~N}\left(r^{2}=0.50, p=0.08 \mathrm{n}=7\right)$. However, dietary $\delta^{15} \mathrm{~N}$ need not be equivalent to the simple site average foliar $\delta^{15} \mathrm{~N}$. For instance, we have observed at several sites that foliar $\delta^{15} \mathrm{~N}$ is significantly lower for $\mathrm{C}_{4}$ grasses (Table 2). At Zizou, the mean foliar $\delta^{15} \mathrm{~N}(10.5 \%$ ) differs from the estimated dietary $\delta^{15} \mathrm{~N}\left(8.2 \%\right.$ ); the latter being determined from the average foliar $\delta^{15} \mathrm{~N}$ weighted by the proportion of grass consumption (as derived from the faecal $\delta^{13} \mathrm{C}$ ). The difference induced by such an adjustment is $0.9 \%$ o for Spitzkoppe (based on 2014 pellet data), 0.3\%o at NK2010 and negligible at 
Omanyne $(0.1 \% \circ)$, where there is no difference between $C_{4}$ grass and $C_{3}$ foliar $\delta^{15} \mathrm{~N}$. Analysis using the estimated dietary $\delta^{15} \mathrm{~N}$ indicates a significant correlation $\left(r^{2}=0.63, p=0.03 n=7\right)$ between dietary $\delta^{15} \mathrm{~N}$ and faecal $\delta^{15} \mathrm{~N}$ with a predicted $3.4 \pm 2.3 \%$ diet-faeces offset (Figure 9) and a gradient not significantly different from $1(0.88 \pm 0.3)$. A comparable strength of relationship between faecal and foliar $\delta^{15} \mathrm{~N}$ was reported by Díaz et al. (2016) for camelid and rodent faeces in the Atacama Desert.
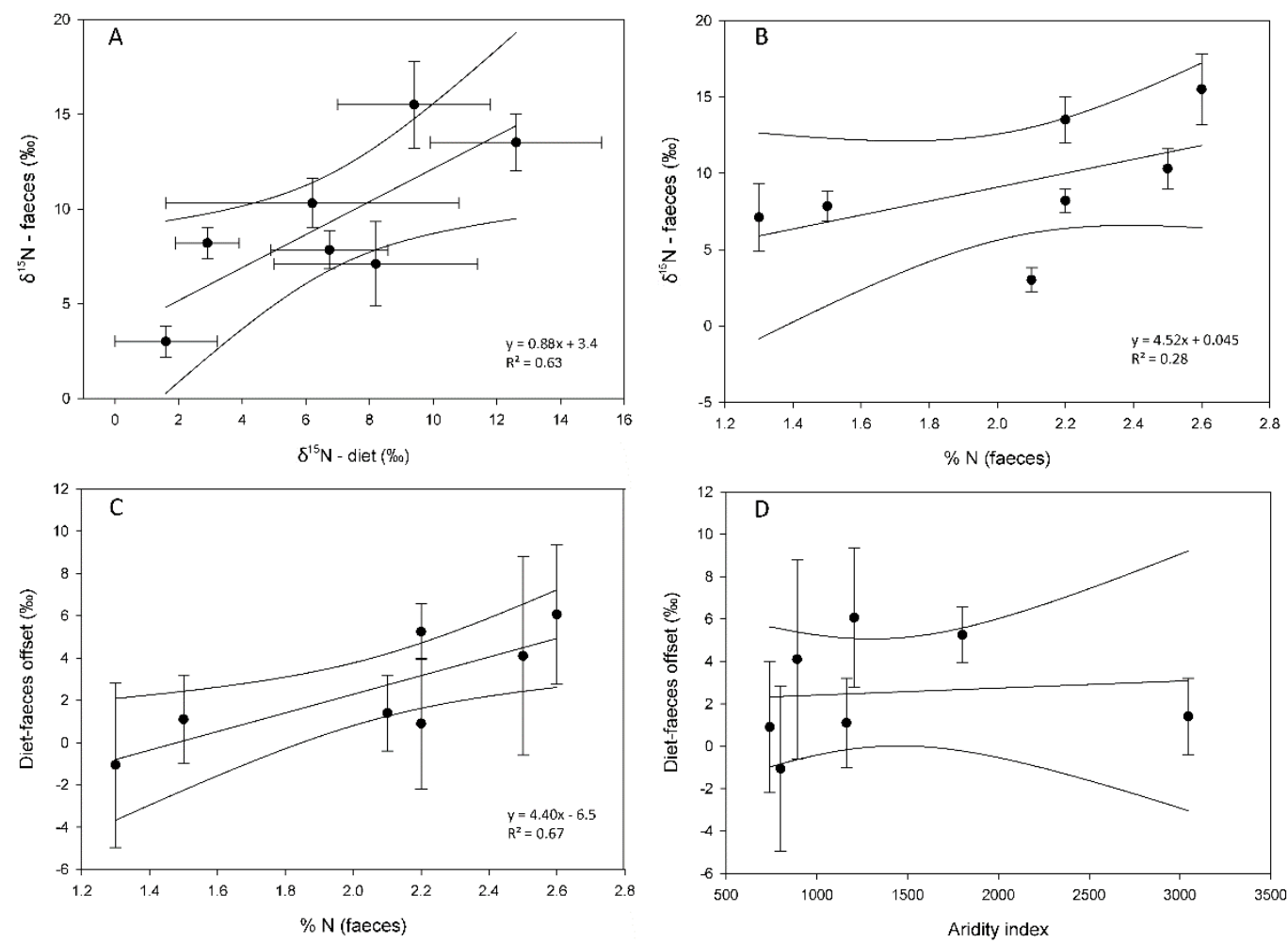

Figure 9: A) Dietary-weighted average $\delta^{15} \mathrm{~N}$ plotted against site average faecal $\delta^{15} \mathrm{~N}$. Standard deviations are plotted. B) Average \% plotted against site average faecal $\delta^{15} \mathrm{~N}$; C) Dietary-faecal offset plotted against \%N; D) Dietary-faecal offset plotted against aridity index (Trabucco and Zomer, 2009). Results of ordinary least-squares regression are shown in each case.

In all cases, sampling biases must be kept in mind. Not all plants in the foraging range of the hyrax colonies were sampled, and samples were not taken throughout the year. Our samples thus may not reflect the full feeding behaviour of the hyraxes, nor the season in which the pellets were deposited. The values presented here are only comparable in the broadest sense. However, Codron and Codron (2009) also demonstrated a relationship between faecal and dietary $\delta^{15} \mathrm{~N}$ for southern African herbivores, although they noted that the relationship is not as strong as that for $\delta^{13} \mathrm{C}$. While 
there are several proposed physiological controls on herbivore tissue $\delta^{15} \mathrm{~N}$, the only additional control of significance for faecal $\delta^{15} \mathrm{~N}$ identified by Codron and Codron (2009) was \% $\mathrm{N}$ in faeces, which can be considered a proxy for dietary protein content (ibid). Dietary protein content has been proposed (along with water conservation strategies) to impact the faecal/urine ${ }^{15} \mathrm{~N}$ mass balance in droughttolerant herbivores (Ambrose, 1991; Codron et al. 2005). In our dataset the relationship between \%N in faeces and faecal $\delta^{15} \mathrm{~N}$ is positive, but not significant $\left(\mathrm{r}^{2}=0.28, p=0.22, \mathrm{n}=7\right.$; Figure 9B). There is, however, a significant positive correlation $\left(r^{2}=0.67 p=0.02 n=7\right)$ between the $\delta^{15} N$ diet-faeces offset and \% $\mathrm{N}$ in faecal pellets (Figure 9C). This implies a dietary protein content control (Tables 2 and 3 ). Greater isotopic diet-tissue discrimination has been reported for higher protein diets (Sponheimer et al. 2003b). Indeed, the lowest offsets are observed at Zizou and NK2010 where we observe significant consumption of grasses (which have low foliar $\% \mathrm{~N}$; Table 2). Additionally, we do not observe any correlation between the diet-faecal offset and aridity (Figure 9D), which might be an anticipated impact of water conservation physiological responses to aridity. This finding is consistent with other studies (e.g. Ugan and Coltraine, 2011).

To link these findings with palaeoenvironmental studies employing hyraceum $\delta^{15} \mathrm{~N}$ we also compared faecal $\delta^{15} \mathrm{~N}$ with hyraceum $\delta^{15} \mathrm{~N}$ from recently-deposited middens (Table S2; Figure 10). As hyraceum is considered to be largely a urinary product, it has been assumed to contain urea, which following mass-balance expectations of some physiological water conservation models may have a $\delta^{15} \mathrm{~N}$ signature anti-correlated with body tissue, or at least generally have a lower $\delta^{15} \mathrm{~N}$ than body tissue (e.g. Sponheimer et al., 2003c and references therein). Here we compare hyraceum with faeces, within which $\mathrm{N}$ is assumed to be primarily derived from animal tissue (e.g. Codron et al., 2005). The number of sites with recent (we have used the last 100 years) midden accretion is limited (Chase et al., 2012), but the relationship between faeces and hyraceum $\delta^{15} \mathrm{~N}$ for these sites is positive and highly significant. The high explanatory power of this relationship $\left(r^{2}=0.93 p<0.001\right)$ suggests that hyraceum $\delta^{15} \mathrm{~N}$ is positively correlated with faecal $\delta^{15} \mathrm{~N}$ across the study region, and by corollary (i.e. Figure $9 \mathrm{~A}$ ), correlated with dietary $\delta^{15} \mathrm{~N}$. Concerning the latter, at present there are only four sites with both recent hyraceum deposits and dietary (foliar) $\delta^{15} \mathrm{~N}$ data (Spitzkoppe, Jaagvlakte, De Rif and Pakhuis Pass). However the data from these four sites indicate a positive correlation between dietary $\delta^{15} \mathrm{~N}$ and hyraceum $\delta^{15} \mathrm{~N}$ (Pearson's $r=0.96, p=0.04$ ). 


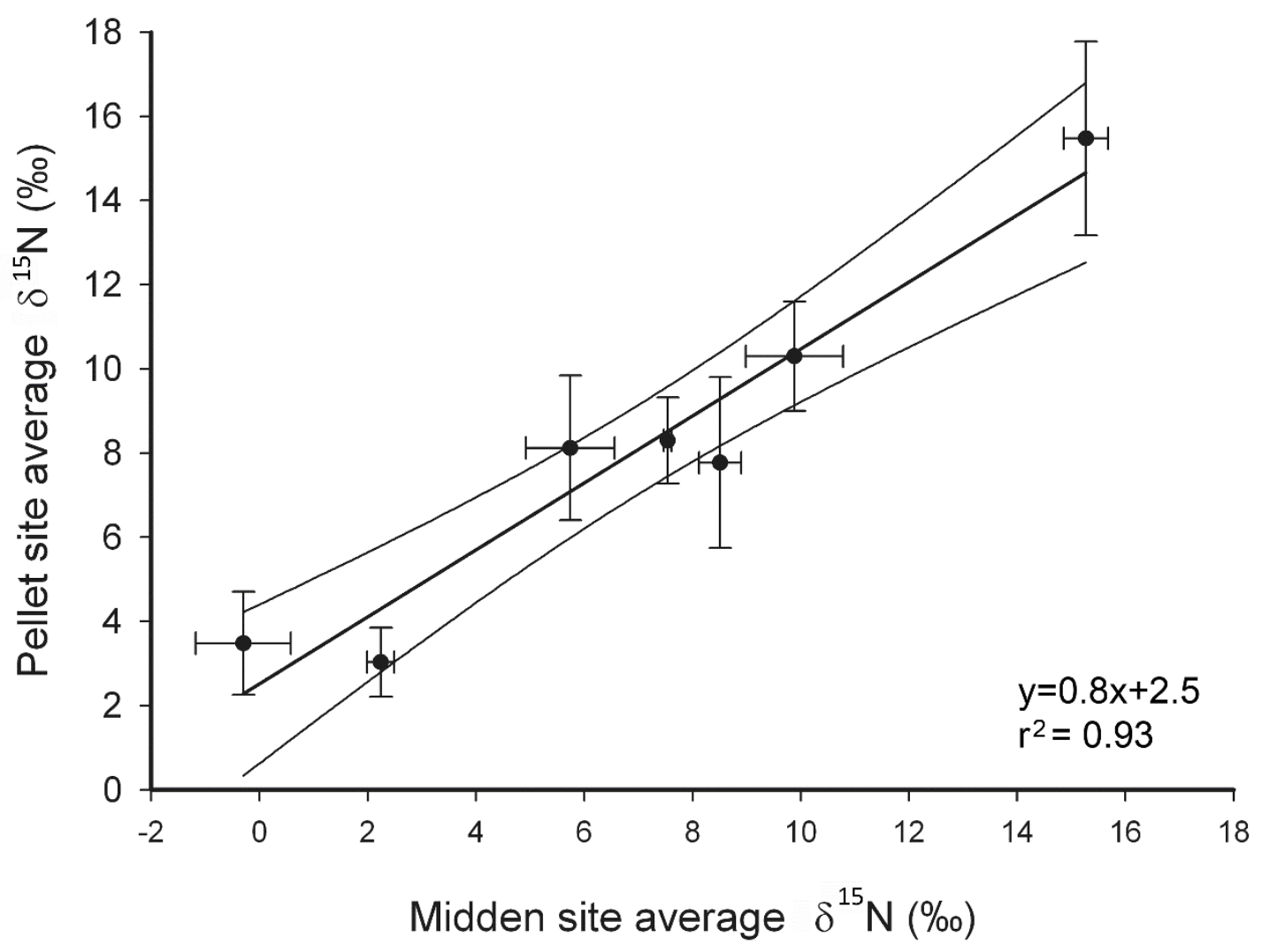

563 Figure 10: Midden (hyraceum) $\delta^{15} \mathrm{~N}$ (site average and standard deviation for the last 100 years; Table 564 S2) plotted against site average and standard deviation of modern faecal $\delta^{15} \mathrm{~N}$. The sites plotted are: 565 Spitzkoppe, De Rif, Marikabi, Seweweekspoort (SWP-1), Jaagvlakte, Pakhuis Pass and Papkuilsfontein.

Overall, these findings suggest a significant role for diet (i.e. source isotopic composition and dietary protein content) in controlling variability in both faecal and hyraceum $\delta^{15} \mathrm{~N}$ (Figure 9A; Figure 10). Furthermore, the strong positive correlations between faecal and foliar $\delta^{15} \mathrm{~N}$ with hyraceum $\delta^{15} \mathrm{~N}$ imply that either: 1 ) the dominant control on $\delta^{15} \mathrm{~N}$ in hyraceum is not related to metabolic effects (e.g. Hartmann, 2011; Murphy and Bowman, 2006) and/or 2) hyraceum is not primarily composed of urea, and the $\mathrm{N}$-containing metabolic products being measured are not affected by water conservation 572 physiological responses. It is noteworthy that modern hyraceum $\delta^{15} \mathrm{~N}$ is higher than dietary (foliar) $573 \delta^{15} \mathrm{~N}$ (Figure 9) but statistically indistinguishable from faecal $\delta^{15} \mathrm{~N}$ at the four sites with the complete set of hyraceum, faecal and foliar $\delta^{15} \mathrm{~N}$ data (Table S2). Furthermore several unrelated (to urea) Ncontaining animal metabolites have been identified within hyraceum (Carr et al., 2010). While this issue needs further study, it is possible that other $\mathrm{N}$ containing components of hyraceum swamp any

$577{ }^{15} \mathrm{~N}$ depleted urea, or that excreted urea is quickly converted to ammonia and volatilised (Schwarcz et al., 1999), and hence is not preserved. 

Anson, 2008).

Palaeoenvironmental reconstructions from hyrax middens have interpreted nitrogen isotope variability within hyraceum as reflecting the impact of climatic changes on soil and plant $\delta^{15} \mathrm{~N}$ in foraging zones around a hyrax colony (Chase et al., 2012). It has been proposed that in desert ecosystems an underlying mechanism driving foliar $\delta^{15} \mathrm{~N}$ variation is soil water availability (Hartman, 2011; Hartman and Danin, 2010; Murphy and Bowman, 2006). At the global scale, increasing foliar $\delta^{15} \mathrm{~N}$ with aridity may reflect the influence of water availability on the 'openness' of the nitrogen cycle (losses relative to the size of the total N pool) (Austin and Vitousek, 1998; Handley et al., 1999). This relationship may breakdown under conditions of the most extreme aridity (Díaz et al. 2016). The foliar $\delta^{15} \mathrm{~N}$ measurements from this study, encompassing seven sites spanning aridity index values from 3045-701 (equivalent to UNEP aridity index 0.3 [semi-arid] to 0.07 [arid]) and mean annual precipitation values from $98 \mathrm{~mm} \mathrm{a}^{-1}$ to $860 \mathrm{~mm} \mathrm{a}^{-1}$ show a scattered, but negative correlation with aridity $\left(r^{2}=0.36 p<0.0001 n=110\right)$ (Figure 11).

For sites with paired foliar/faecal $\delta^{15} \mathrm{~N}$ data (Figure 11) we can explore the roles of climate and metabolic affects in more detail (e.g. Heaton 1987) as it can be hypothesised that with increasing aridity any additional physiological response to water stress (resulting in the preferential excretion of ${ }^{15} \mathrm{~N}$-depleted urea via urine) will result in a steeper gradient in the relationship between faecal $\delta^{15} \mathrm{~N}$ and aridity compared to that between foliar $\delta^{15} \mathrm{~N}$ and aridity. Previous studies have reported bone collagen $\delta^{15} \mathrm{~N}$ to decrease by 1.1 to $1.3 \%$ per $100 \mathrm{~mm}$ increase in rainfall, which was inferred to be three times the gradient observed for vegetation $\delta^{15} \mathrm{~N}$ (see Ambrose, 1991; cf. Schwarcz et al., 1999 and references therein). More recent studies have implied a consistent offset between body tissue and foliar $\delta^{15} \mathrm{~N}$ across aridity gradients, implying no significant metabolic effect (Schwarcz et al., 1999; Hartman, 2011; Murphy and Bowman, 2006). In our data (Figure S4), we observe gradients of $-2.5 \pm$ $0.2 \%$ per $100 \mathrm{~mm}$ of rainfall for faecal $\delta^{15} \mathrm{~N}$ and $-3.8 \pm 0.4 \%$ per $100 \mathrm{~mm}$ of rainfall for foliar $\delta^{15} \mathrm{~N}$. In fact, when site average $\delta^{15} \mathrm{~N}$ values are used (as opposed to linear regression slopes derived using all measured data points) these gradients are essentially identical (-3.1 $\pm 0.8 \%$ op $100 \mathrm{~mm}$ rainfall for diet-weighted foliar $\delta^{15} \mathrm{~N},-3.5 \pm 1.7 \%$ of faecal $\delta^{15} \mathrm{~N}$ and $-3.4 \pm 0.8 \%$ o for site average foliar $\delta^{15} \mathrm{~N}$ ). This is consistent with figure 9D. We do, however, note that our data are restricted to relatively arid environments and that these relationships may become weaker under increased humidity (Pate and 

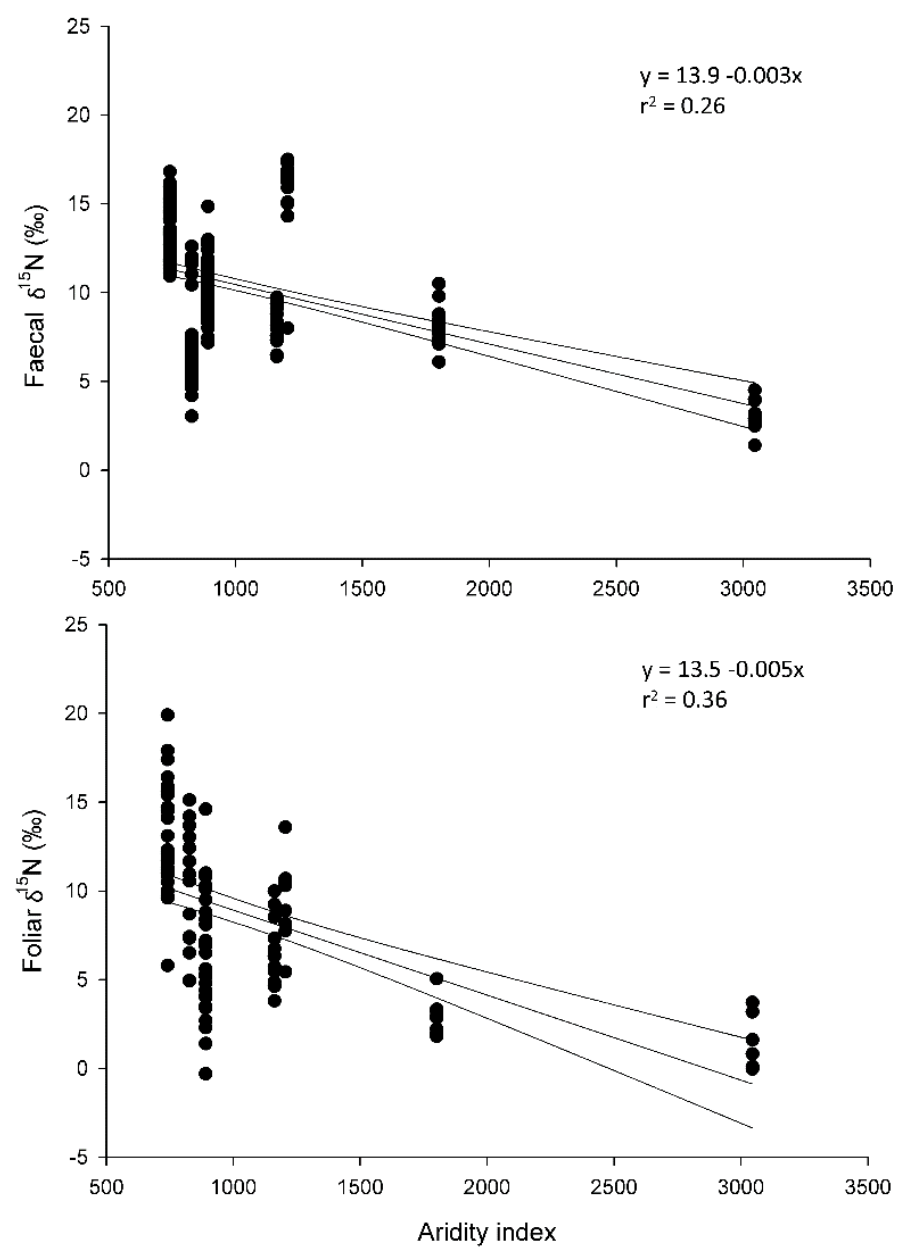

610

Figure 11: Relationship between aridity index and faecal $\delta^{15} \mathrm{~N}$ and plant $\delta^{15} \mathrm{~N}$ for sites where the two 612 were jointly sampled. The sites plotted are NK2010, Jaagvlakte, De Rif, Pakhuis Pass, Omanyne, Zizou 613 and Spitzkoppe. Minimising the leverage effect of the most humid site (De Rif) using log aridity index 614 also results statistically significant relationships $\left(r^{2}=0.43\right.$ and 0.25 for foliar and faecal data respectively)

An aridity index that incorporates temperature and evaporative effects on water availability may be a more appropriate way to consider these processes (Hartman, 2011; Murphy and Bowman, 2006). The gradients for paired faecal/foliar $\delta^{15} \mathrm{~N}$ data using aridity index show comparable relations to those seen using mean annual rainfall; i.e. the gradient is steeper for foliar $\delta^{15} \mathrm{~N}$ than for faecal $\delta^{15} \mathrm{~N}$

621 (Figure 11), although the role of high Al outlier site (De Rif) should be kept in mind. Considering the total faecal $\delta^{15} \mathrm{~N}$ dataset across every site, we observe a weak, but significant $\left(r^{2}=0.16 p<0.00001\right.$ $\mathrm{n}=651$ ) negative correlation with aridity index (Figures 11 and 12). Two outlier sites contribute to the low explanatory power of this relationship (Figure 12) - SWP-3 and Baviaanskloof (BK1\&2). As noted 
625 previously, the former is located in the sheltered valley bottom (see above) and the Al value may not 626 be representative of the true water availability at this location. The inter-site scatter in faecal $\delta^{15} \mathrm{~N}$ in 627 the Fynbos biome has already been noted (Figure 5) and the relationship between faecal $\delta^{15} \mathrm{~N}$ and 628 climate is markedly stronger $\left(r^{2}=0.30 p<0.00001 n=465\right)$ if sites from the Fynbos are excluded from 629 the analyses (Figure 12). A critical caveat is that gridded climate data are limited by interpolation based 630 on discrete, and sometimes distant, weather station data (e.g. Hijmans et al., 2005) and the precision 631 of the data is generally resolved to $1 \mathrm{~km}$ or greater grid cells, which cannot adequately reflect the 632 diversity of microclimates and local-scale variability in soil bodies (e.g. water, $\mathrm{C}$ and $\mathrm{N}$ availability). This 633 is potentially significant in areas of high relief and variability in aspect, such as the valleys and cliffs 634 that many midden sites are located (well-illustrated at Witsand) and is likely to particularly affect sites 635 in the Cape Fold Belt Mountains (cf. BK1 and BK2). Thus, even if climatic factors were the sole 636 mechanisms for determining soil/plant $\delta^{15} \mathrm{~N}$, the nature of climatic data employed would necessarily 637 generate significant data scatter. 

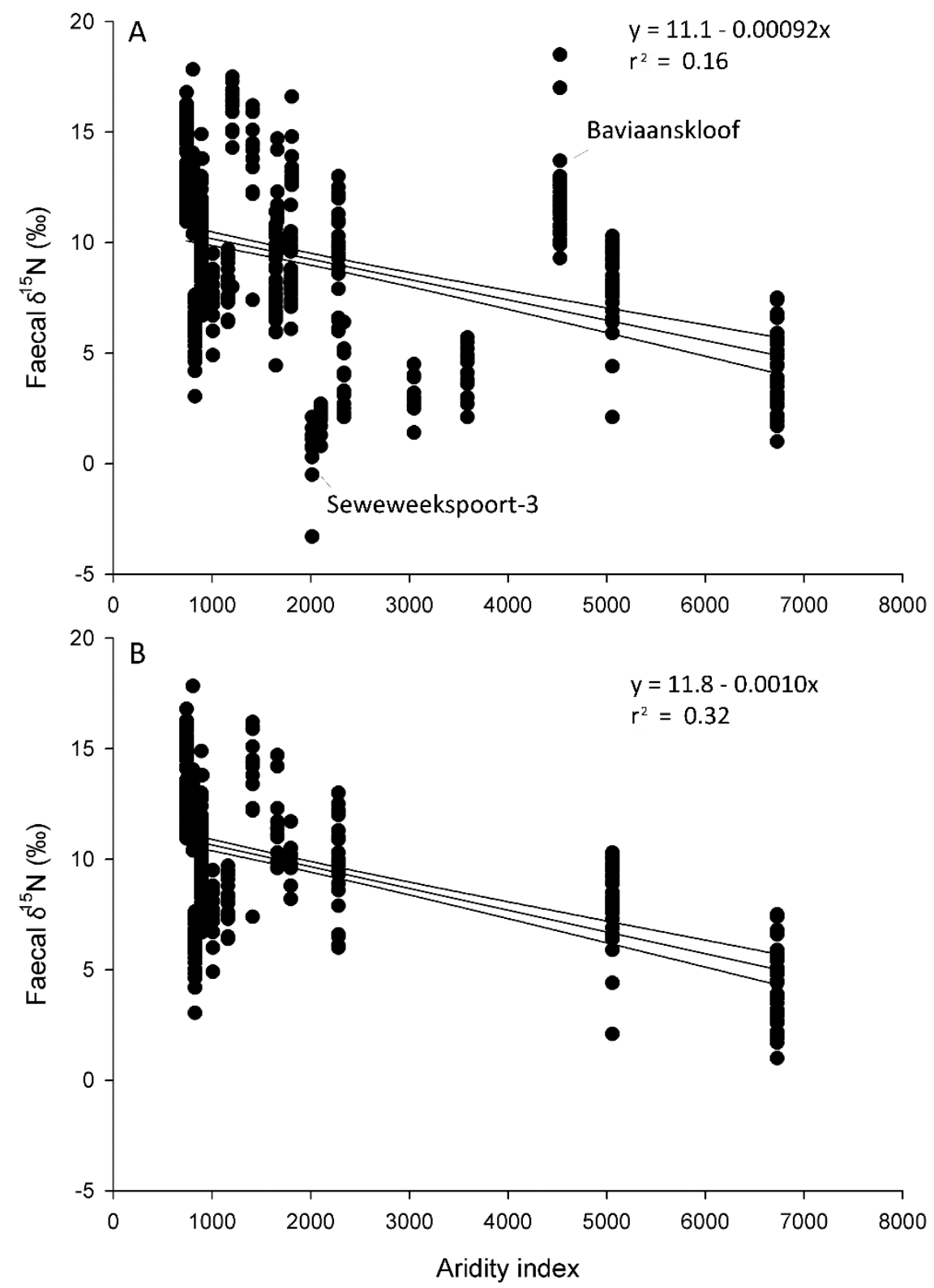

638

639 Figure 12: A) All faecal $\delta^{15} \mathrm{~N}$ determinations plotted in relation to aridity index. B) All faecal $\delta^{15} \mathrm{~N}$ 640 determinations plotted with the exception of sites located in the Fynbos Biome. Inappropriate 641 attribution of the aridity index to sites in the topographically-complex Cape Fold Belt region may 642 account for the weaker explanatory power when including the Fynbos biome. Using log aridity index 643 also results statistically significant relationships $\left(r^{2}=0.20\right.$ and 0.30 for all sites and all non-fynbos sites 644 respectively) 
647 The $\delta^{13} \mathrm{C}$ data suggest that $P$. capensis is an opportunistic feeder, grazing when palatable grass is 648 available, but primarily limited to browsing. This is consistent with existing observations (Lensing, 649 1983; Fourie, 1983; Scott and Vogel, 2000), but the wider geographic spread of our data suggests such 650 inferences are generally valid for much of the hyrax's habitat. This is also consistent with some 651 interpretations of hyrax midden $\delta^{13} \mathrm{C}$ records from the Savanna Biome, whereby a model of greater 652 wet season $C_{4}$ grass consumption was extended to consider longer-term fluctuations in the 653 duration/intensity of the wet season (Chase et al. 2009; 2010).

The $\delta^{15} \mathrm{~N}$ data overall imply: 1) faeces and hyraceum $\delta^{15} \mathrm{~N}$ are controlled largely by diet (i.e. foliar $\delta^{15} \mathrm{~N}$ and potentially foliar $\mathrm{N}$ content), 2) that the previously-reported negative relationship between aridity and herbivore/foliar $\delta^{15} \mathrm{~N}$ is observed in southern African hyrax habitats, 3) a limited role for water-conservation metabolic effects. The specific drivers of the offsets between between foliar (dietary) $\delta^{15} \mathrm{~N}$, faecal $\delta^{15} \mathrm{~N}$ and hyraceum $\delta^{15} \mathrm{~N}$ are difficult to interpret, but a substantial (though not necessarily singular) role for diet in driving hyrax faecal and midden $\delta^{15} \mathrm{~N}$ variability is implied (Figure 9) by the comparable slopes of the faecal/foliar $\delta^{15} \mathrm{~N}-\mathrm{MAP} /$ aridity index relationships (Figures 9D, 11 and S4) and the positive correlation between faecal $\delta^{15} \mathrm{~N}$ and hyraceum $\delta^{15} \mathrm{~N}$ (Figure 10). The $\mathrm{N}$ (protein) content of the hyrax diet may be significant (Figure 9c; Sponheimer et al., 2003b), but the broader impact of this latter factor is difficult to assess as it can be anticipated that the animal is able to meet its protein needs and at most sites (perhaps excepting Zizou) this can be achieved through varying the proportions of (fresh) graze and browse through time. Strong evidence for a metabolic effect is not readily apparent, although the the strong correlation between faecal $\delta^{15} \mathrm{~N}$ and hyraceum $\delta^{15} \mathrm{~N}$, and the comparable diet-faeces and diet-hyraceum $\delta^{15} \mathrm{~N}$ offsets could also be explained by an absence of urea in the measured hyraceum $\delta^{15} \mathrm{~N}$.

Additionally, in the savanna biome (and NK2010 in the Nama Karoo), we observe that $\delta^{15} \mathrm{~N}$ and $\% \mathrm{~N}$ can be lower in $\mathrm{C}_{4}$ grasses compared to $\mathrm{C}_{3}$ shrubs and trees at the same site (Table 2 ), which either singularly or together may have attendant (i.e. lowering) impacts on herbivore $\delta^{15} \mathrm{~N}$ and thus 672 hyraceum $\delta^{15} \mathrm{~N}$ (e.g. Sponheimer et al., 2003b). For the savanna biome as a whole faecal $\delta^{13} \mathrm{C}$ is negatively correlated with faecal $\delta^{15} \mathrm{~N}\left(r^{2}=0.33\right)$, although this relationship is strongly affected by the data from Zizou ( $r^{2}=0.14$ without Zizou) where higher grass consumption is inferred. There are weaker 675 (Grassland; $r^{2}=0.26$ ), opposing (i.e. positive correlation and $r^{2}=0.47$; Nama Karoo) or insignificant 676 (fynbos; $r^{2}=<0.01$ ) relationships between faecal $\delta^{13} \mathrm{C}$ and $\delta^{15} \mathrm{~N}$ in the other biomes, presumably 677 reflecting far more minor/lack off of $\mathrm{C}_{4}$ vegetation consumption in these environments (no faecal pellet has a $\delta^{13} \mathrm{C}$ higher than $-21 \%$ in the Grassland or Nama Karoo biomes). 

dataset and potential seasonal variability in grass $\% \mathrm{~N}$ and $\delta^{15} \mathrm{~N}$ (Codron et al., 2013) and so in some environments disentangling the specific roles of $\mathrm{C}_{4}$ contribution to diet versus climate (remembering that the two are clearly not independent variables) in driving hyraceum palaeo- $\delta^{15} \mathrm{~N}$ records could be challenging. Notwithstanding, both effects are consistent with palaeoecological interpretations presented for the savanna middens. That is, as the dietary contribution of fresh and palatable $\mathrm{C}_{4}$ grasses increases with water availability we would anticipate a reduction in hyraceum $\delta^{15} \mathrm{~N}$ and an increase $\delta^{13} \mathrm{C}$ (as is observed; Chase et al., 2009; 2010). However, the data demonstrate a need to consider the context of each individual midden as the proportional contribution of grasses to diets in the savanna biome can be variable (e.g. Zizou). The dietary data presented thus far are derived only from foliar $\delta^{15} \mathrm{~N}$ and further work concerning other plant parts may allow these relationships to be refined.

In the Fynbos, diet is dominated by $C_{3}$ vegetation and with the exception of SWP-2 there is little evidence of CAM plant consumption. The SWP-2 data suggest that this cannot always be discounted, and minor ( $<1 \%$ of consumed material) consumption of CAM plants (Aloe) has been observed in the dry season (Fourie, 1983). In terms of hyraceum isotope records, the resulting shift in $\delta^{13} \mathrm{C}$ due to CAM consumption would likely parallel the impact of water-use efficiency changes in $C_{3}$ plants (Chase et al., 2011), and long-term trends in midden records (pollen and isotopes) have indicated potentially increased CAM plant representation during certain periods (Chase et al., 2015b).

Finally, the importance of the time/space averaging effects, as occurs when sampling hyraceum, is demonstrated. The inter-sample scatter in hyraceum $\delta^{13} \mathrm{C} / \delta^{15} \mathrm{~N}$ (Table S2; site standard deviations of $\sim 0.5 \%$ ) is lower than the total scatter in faecal $\delta^{13} \mathrm{C} / \delta^{15} \mathrm{~N}$ (site standard deviations of $\sim 1.5 \%$ ), which is in turn lower than the variability in foliar $\delta^{13} \mathrm{C} / \delta^{15} \mathrm{~N}$ (site standard deviations of $\sim 2.5 \%$ o). The scatter in foliar $\delta^{15} \mathrm{~N}$ probably reflects a combination plant species effects and local topographic/hydrological/soil nutrient ( $\mathrm{N}$ availability) controls on soil $\delta^{15} \mathrm{~N}$ (Craine et al., 2012; Handley et al., 1999; Ugan and Coltraine, 2011).

\section{Conclusions}

706 These data represent a first attempt to refine, from the perspective of stable isotopes, our understanding of rock hyrax diet and behaviour. This is of particular interest given the use of rock hyrax middens as arid zone palaeoenvironmental archives. Faecal $\delta^{13} \mathrm{C}$ demonstrates that the rock hyrax is largely a browser but is (probably) an opportunistic mixed feeder, consuming $\mathrm{C}_{4}$ grasses during periods of the year when this food source is available/most nutritious. This is consistent with 
observations of animal behaviour. Inter-site faecal $\delta^{15} \mathrm{~N}$ variability is large, particularly in the Fynbos. The absolute values of faecal $\delta^{15} \mathrm{~N}$ are high relative other African herbivores, but they correlate with dietary (foliar) $\delta^{15} \mathrm{~N}$, with an offset consistent with expected trophic level enrichment. The diet-faeces $\delta^{15} \mathrm{~N}$ offset - which is predicted to increase with aridity if water-conservation metabolic effects have a significant impact on the $\delta^{15} \mathrm{~N}$ of animal tissue - is uncorrelated with climate, but is correlated with \%N in faecal pellets. Faecal $\delta^{15} \mathrm{~N}$ (and thus foliar $\delta^{15} \mathrm{~N}$ ) correlates strongly with hyraceum $\delta^{15} \mathrm{~N}$. Foliar $\delta^{15} \mathrm{~N}$ data are available for seven sites across three biomes and correlate significantly (albeit with scatter) with aridity. Together these observations do not presently imply a substantial role for waterconservation metabolic processes in driving hyraceum $\delta^{15} \mathrm{~N}$ variation and/or that measured nitrogen within hyraceum is representative of body tissue $\mathrm{N}$ other than urea $\mathrm{N}$. The data presently available for modern hyrax habitats are thus broadly in agreement interpretations of hyraceum $\delta^{15} \mathrm{~N}$ and $\delta^{13} \mathrm{C}$ records in palaeoenvironmental reconstructions.

\section{Acknowledgements}

Funding was received from the European Research Council (ERC) under the European Union's Seventh Framework Programme (FP7/2007-2013)/ERC Starting Grant "HYRAX", grant agreement no. 258657. Additional funding to support plant sampling was provided by the Leverhulme Trust (Grant F/00 212/AF). We thank Tracey Nowell for assistance in the field and Sammy Hargreaves for helping with the sample preparation. Two reviewers are thanked for their constructive comments.

\section{References}

Ambrose, S.H., 1986. Stable carbon and nitrogen isotope analysis of human and animal diet in Africa. Journal of Human Evolution 15, 707-731.

Ambrose, S.H., 1991. Effects of diet, climate and physiology on nitrogen isotope abundances in terrestrial foodwebs. Journal of Archaeological Science 18, 293-317

Ambrose, S.H., DeNiro, M.J., 1986a. The isotopic ecology of East African mammals. Oecologia 69, 395406.

Ambrose, S.H., DeNiro, M.J., 1986b. Reconstruction of African human diet using bone collagen carbon and nitrogen isotope ratios. Nature 319, 321-324.

Ambrose, S.H., DeNiro, M.J., 1987. Bone nitrogen isotopic composition and climate. Nature 325, 201.

Aranibar, J.N., Anderson, I.C. Epstein, H.E. Feral., C.J.W Swap, R.J. Ramontsho, J., Macko, S.A., 2008. Nitrogen isotope composition of soils, $C_{3}$ and $C_{4}$ plants along land use gradients in southern Africa. Journal of Arid Environments 72, 326-337

Austin, A.T., Vitousek, P.M., 1998. Nutrient dynamics on a precipitation gradient in Hawai'i. Oecologia 113, 519-529. 
Botha, M.S., Stock, W.D., 2005. Stable isotope composition of faeces as an indicator of seasonal diet selection in wild herbivores in southern Africa. South African Journal of Science 101, 371-374

Brown, K.J., Downs, C.T., 2005. Seasonal behavioural patterns of free-living rock hyrax (Procavia capensis). Journal of the Zoological Society of London 265, 311-326

Carr, A.S., Boom, A., Chase, B.M., 2010. The potential of plant biomarker evidence derived from rock hyrax middens as an indicator of palaeoenvironmental change. Palaeogeography Palaeoclimatology Palaeoecology 285, 321-330

Carr, A.S., Boom, A., Chase, B.M., Meadows, M.E., Roberts, Z.E. Britton, M.N., Cumming, A.M.J., 2013. Biome-Scale characterisation and differentiation of semi-arid and arid zone soil organic matter compositions using pyrolysis-GC/MS analysis. Geoderma 200-201, 189-201

Carr, A.S., Boom, A., Grimes. H.L., Chase, B.M., Meadows, M.E., Harris, A., 2014. Leaf wax $n$-alkane distributions in arid zone South African flora: Environmental controls, chemotaxonomy and palaeoecological implications. Organic Geochemistry 67, 72-84.

Chase, B.M., Meadows, M.E., Scott, L., Thomas, D.S.G., Marais, E., Sealy, J., Reimer, P.J., 2009. A record of rapid Holocene climate change preserved in hyrax middens from southwestern Africa. Geology 37, 703-706.

Chase, B.M., Meadows, M.E., Carr, A.S., Reimer, P.J., 2010. Evidence for progressive Holocene aridification in southern Africa recorded in Namibian hyrax middens: implications for African Monsoon dynamics and the "African Humid Period". Quaternary Research 74, 36-45.

Chase, B.M., Quick, L.J., Meadows, M.E., Scott, L., Thomas, D.S.G., Reimer, P.J., 2011. Late-glacial interhemispheric climate dynamics revealed in South African hyrax middens. Geology 39, 1922.

Chase, B.M., Scott, L., Meadows, M.E., Gil-Romera, G., Boom, A., Carr, A.S., Reimer, P.J., Truc, L., Valsecchi, V., Quick. L.J., 2012. Rock hyrax middens: a palaeoenvironmental archive in southern African drylands. Quaternary Science Reviews 56, 1-19

Chase, B.M., Boom, A., Carr, A.S., Meadows, M.E., Reimer, P.J., 2013. Holocene climate change in southernmost South Africa: rock hyrax middens record shifts in the southern westerlies. Quaternary Science Reviews 82, 199-205

Chase, B.M., Lim, S., Chevalier M., Boom, A., Carr, A.S., Meadows, M.E., Reimer, P.J., 2015a. Influence of tropical easterlies in southern Africa's winter rainfall zone during the Holocene. Quaternary Science Reviews 107, 138-148

Chase, B.M., Boom, A., Carr, A.S., Carré, M., Chevalier, M., Meadows, M.E., Pedro, J.B., Stager, J.C., Reimer, P.J., 2015b. Evolving southwest African response to abrupt de-glacial North Atlantic climate change events. Quaternary Science Reviews 121, 132-136

Codron, D., Codron, J., 2009. Reliability of $\delta^{13} \mathrm{C}$ and $\delta^{15} \mathrm{~N}$ in faeces for reconstructing savanna herbivore diet. Mammalian Biology 74, 36-48.

Codron, D., Codron, J., Lee-Thorp, J.A., Sponheimer, M., de Ruiter, D., 2005. Animal diets in the Waterberg based on stable isotopic composition of faeces. South African Journal of wildlife Research 35, 43-52.

Codron, D., Codron, J., 2009. Reliability of $\delta^{13} \mathrm{C}$ and $\delta^{15} \mathrm{~N}$ in faeces for reconstructing savanna herbivore diet. Mammalian Biology-Zeitschrift für Säugetierkunde 74, 36-48. 
Codron, D., Sponheimer, M., Codron, J., Hammer, S., Tschuor, A., Braun, U., Bernasconi, S.A., Claus, M., 2012. Tracking the fate of digesta ${ }^{13} \mathrm{C}$ and ${ }^{15} \mathrm{~N}$ compositions along the ruminant gastrointestinal tract: Does digestion influence the relationship between diet and faeces?

Codron, J., Lee-Thorp, J. A. Sponheimer, M. Codron, D., 2013. Plant stable isotope composition across habitat gradients in a semi-arid savanna: implications for environmental reconstruction. Journal of Quaternary Science 28, 301-310

Craine, J.M., Elmore, A.J., Aidar, M.P., Bustamante, M., Dawson, T.E., Hobbie, E.A., Kahmen, A., Mack, M.C., McLauchlan, K.K., Michelson, A., Nardoto, G.B., Pardo, L.H., Peñuelas, J., Reich, P.B., Schuur, E.A.G., Stock, W.D., Templer, P.H., Virginia, R.A., Welker, J.M. Wright, I.J., (2009). Global patterns of foliar nitrogen isotopes and their relationships with climate, mycorrhizal fungi, foliar nutrient concentrations, and nitrogen availability. New Phytologist, 183, 980992.

Craine, J.M., Towne, E.G., Ocheltree, T.W., Nippert, J.B., 2012 Community traitscape of foliar nitrogen isotopes reveals $\mathrm{N}$ availability patterns in a tallgrass prairie. Plant Soil 356, 395-403.

Craine, J.M. Brookshire, E.N.J., Cramer, M.D., Hasselquist, N.J., Kopa, K., Marin-Spiotta, E., Wang, L., 2015. Ecological interpretations of nitrogen isotope ratios of terrestrial plants and soils. Plant Soil 10.1007/s11104-015-2542-1

DeNiro, M.J., Epstein, S., 1978. Carbon isotopic evidence for different feeding patterns in two hyrax species occupying the same habitat. Science $201,906-908$.

Díaz, F.P., Frugone, M., Gutiérrez, R.A., Latorre, C., 2016. Nitrogen cycling in an extreme hyperarid environment inferred from $\delta^{15} \mathrm{~N}$ analyses of plants, soils and herbivore diet. Scientific Reports 6, 22226 doi: 10.1038/srep2226

Fourie, L.J., 1983. The population dynamics of the rock hyrax Procavia capensis (pallas, 1766) in the Mountain Zebra National Park. Unpublished PhD thesis, Rhodes University, South Africa.

Gil-Romera, G., Scott, L., Marais, E., Brook, G.A., 2006. Middle- to late-Holocene moisture changes in the desert of northwest Namibia derived from fossil hyrax dung pollen. Holocene 16, 10731084.

Gil-Romera, G., Scott, L., Marais, E., Brook, G.A., 2007. Late Holocene environmental change in the northwestern Namib Desert margin: new fossil pollen evidence from hyrax middens. Palaeogeography, Palaeoclimatology, Palaeoecology 249, 1-17.

Grunow, J.O., Pienaar, A.J., Breytenbach, C., 1970. Long term nitrogen application to veld in South Africa. Proceedings of the Annual Congresses of the Grassland Society of Southern Africa 5, 75-90.

Handley, L.L., Austin, A.T., Stewart, G.R., Robinson, D., Scrimgeour, C.M., Raven, J.A., Heaton, T.H.E., Schmidt, S., 1999. The ${ }^{15} \mathrm{~N}$ natural abundance $\left(\delta^{15} \mathrm{~N}\right)$ of ecosystem samples reflects measures of water availability. Functional Plant Biology 26, 185-199.

Hartman, G., 2011. Are elevated $\delta^{15} \mathrm{~N}$ values in herbivores in hot and arid environments caused by diet or animal physiology? Functional Ecology 25, 122-131.

Hartman, G., Danin, A., 2010. Isotopic values of plants in relation to water availability in the Eastern Mediterranean region. Oecologia 162, 837-852. 
Heaton, T.H.E., 1987. The ${ }^{15} \mathrm{~N} /{ }^{14} \mathrm{~N}$ ratios of plants in South Africa and Namibia: relationship to climate and coastal/saline environments. Oecologia 74, 236-246.

Heaton, T.H.E., Vogel, J.C., von la Chevallerie, G., Collet, G., 1986. Climate influence on the isotopic composition of bone nitrogen. Nature 322, 822-823.

Hijmans, R., Cameron, S.E., Parra, J.L., Jones, P.G., Jarvis, A., 2005. Very high resolution interpolated climate surfaces for global land areas. International Journal of Climatology 25, 1965-1978.

Hoeck, H.N., 1975. Differential feeding behaviour of the sympatric hyrax: (Procavia johnstoni and Heterohyrax brucei). Oecologia 22, 15-47.

Kotler, B.P., Brown, J.S., Knight, M.H., 1999. Habitat and patch use by hyraxes: there's no place like home? Ecology Letters 2, 82-88.

Lensing, J.E., 1983. Feeding strategy of the rock hyrax and its relation to the rock hyrax problem in southern South West Africa. Madoqua 13, 177-196.

Mucina, L., Rutherford, M.C., 2006. The vegetation of South Africa, Lesotho and Swaziland, Strelitzia 19: South African National Biodiversity Institute, Pretoria.

Murphy, B.P., Bowman, D.M.J.S., 2006. Kangaroo metabolism does not cause the relationship between bone collagen $\delta^{15} \mathrm{~N}$ and water availability. Functional Ecology 20, 1062-1069.

Pate, F.D., Anson, T.J., 2008. Stable nitrogen isotope values in arid-land Kangaroos correlated with mean annual rainfall: potential as a palaeoclimatic indicator. International Journal of Osteoarchaeology 18, 317-326.

Sale, J.B., 1965. The feeding behaviour of rock hyraces (genera Procavia and Heterohyrax) in Kenya. African Journal of Ecology 3, 1-18.

Schoeninger, M.J., DeNiro, M.J., 1984. Nitrogen and carbon isotopic composition of bone collagen from marine and terrestrial animals. Geochimica et Cosmochimica Acta 48, 625-639.

Schwarcz, H.P., Dupras, T.L., Fairgrieve, S.I. 1999. ${ }^{15} \mathrm{~N}$ enrichment in the Sahara: in search of a global relationship. Journal of Archaeological Science 26, 629-636.

Scott, L., 1990. Hyrax (Procaviidae) and dassie rat (Petromuridae) middens in palaeoenvironmental studies in Africa, In: Betancourt, J.L., van Devender, T.R., Martin, P.S. (Eds.), Packrat Middens: The Last 40,000 Years of Biotic Change. University of Arizona Press, Tucson, pp. 408-427.

Scott, L., 1996. Palynology of hyrax middens: 2000 years of palaeoenvironmental history in Namibia. Quaternary International 33, 73-79.

Scott, L., Bousman, C.B. 1990. Palynological analysis of hyrax middens from Southern Africa. Palaeogeography, Palaeoclimatology, Palaeoecology 76, 367-379

Scott, L., Vogel, J.C., 2000. Evidence for environmental conditions during the last 20,000 years in southern Africa from ${ }^{13} \mathrm{C}$ in fossil hyrax dung. Global and Planetary Change 26, 207-215

Scott, L., Marais, E., Brook, G.A., 2004. Fossil hyrax dung and evidence of Late Pleistocene and Holocene vegetation types in the Namib Desert. Journal of Quaternary Science 19, 829-832.

Scott, L., Woodborne, S., 2007a. Pollen analysis and dating of Late Quaternary faecal deposits (hyraceum) in the Cederberg, Western Cape, South Africa. Review of Palaeobotany and Palynology 144, 123-134. 
Scott, L., Woodborne, S., 2007b. Vegetation history inferred from pollen in Late Quaternary faecal deposits (hyraceum) in the Cape winter-rain region and its bearing on past climates in South Africa. Quaternary Science Reviews 26, 941-953

Sealy, J.C., van der Merwe, N.J., Thorp, J.A.L., Lanham, J.L., 1987. Nitrogen isotopic ecology in southern Africa: implications for environmental and dietary tracing. Geochimica et Cosmochimica Acta 51, 2707-2717.

Skinner, J.D., Chimimba, C.T., 2005. The mammals of the southern African sub-region. Cambridge University Press $814 p$

Szpak, P., White, C.D., Longstaffe, F.J., Millaire, J-F, Vásquez-Sánchez, V.F., 2013. Carbon and nitrogen isotopic survey of northern Peruvian plants: Baselines for paleodietary and paleoecological Studies. PLoS ONE 8(1): e53763. doi:10.1371/journal.pone.0053763

Sponheimer, M., Robinson, T., Ayliffe, L., Passey, B., Roeder, B., Shipley, L., Lopez, E., Cerling, T., Dearing, D., Ehleringer, J., 2003a. An experimental study of carbon-isotope fractionation between diet, hair, and feces of mammalian herbivores. Canadian Journal of Zoology 81, 871-876.

Sponheimer, M., Robinson, T., Ayliffe, L., Roeder, B., Hammer, J., West, A., Passey, B., Cerling, T., Dearing, D. \& Ehleringer, J., 2003b. Nitrogen Isotopes in Mammalian Herbivores: Hair $\delta^{15} \mathrm{~N}$ Values from a Controlled-Feeding Study. International Journal of Osteoarchaeology $13,80-$ 87

Sponheimer, M, Robinson, T.F., Roeder, B.L., Passey, B.H., Ayliffe, L.K., Cerling, T.E., Dearing M.D., Ehleringer, J.R., 2003c. An experimental study of nitrogen flux in llamas: is ${ }^{14} \mathrm{~N}$ preferentially excreted? Journal of Archaeological Science 30, 1-7

Still, C.J., Powell, R.L., 2010. Continental-scale distributions of vegetation stable carbon isotope ratios. In West, J.B., Bowen, G.J., Dawson, T.E., Tu, K.P. (Eds). Isoscapes. Springer, Netherlands. pp. 179-193

Sutoh, M., Koyama, T. Yoneyama, T., 1987. Variations of natural ${ }^{15} \mathrm{~N}$ abundances in the tissues and digest of domestic animals. Radioisotopes $36,74-77$

Tieszen, L., Hein, D., Qvortrup, S., Troughton, J., Imbamba, S., 1979. Use of $\delta^{13} \mathrm{C}$ values to determine vegetation selectivity in East African herbivores. Oecologia 37, 351-359.

Trabucco, A., and Zomer, R.J., 2009. Global Aridity Index (Global-Aridity) and Global Potential EvapoTranspiration (Global-PET) Geospatial Database. CGIAR Consortium for Spatial Information. Published online, available from the CGIAR-CSI GeoPortal at: http://www.csi.cgiar.org.

Ugan, A., Coltrain, J., 2011. Variation in collagen stable nitrogen values in black-tailed jackrabbits (Lepus californicus) in relation to small-scale differences in climate, soil, and topography. Journal of Archaeological Science 38, 1417-1429.

Vogel, J.C., 1978. Isotopic assessment of the dietary habits of ungulates. South African Journal of Science 74, 298-301.

World Wildlife Fund (2016) Global Ecoregions dataset. http://www.worldwildlife.org/biomes Accessed June 2016. 
Table 1: Site information and coordinates. Sites are listed by biome with vegetation types obtained from Mucina and Rutherford (2006) with the exception of sites marked ${ }^{1}$, which were derived from the World Wildlife Fund (2016) Ecoregions.

908

Table 2: $C_{3}$ and $C_{4}$ plant foliar $\delta^{13} C$ and $\delta^{15} \mathrm{~N}$. Differences in $\delta^{15} \mathrm{~N}$ and $\% \mathrm{~N}$ between $\mathrm{C}_{3}$ and $\mathrm{C}_{4}$ plants at Spitzkoppe, Zizou, Omanyne and NK2010 are all statistically significant (i.e. Mann-Whitney p <0.05) except for Omanyne $\delta^{15} \mathrm{~N}$ (Mann-Whitney $\mathrm{U}=100.5$, two tailed $\mathrm{p}=0.3$ ). *Excluding CAM specimen for $\delta^{13} \mathrm{C}$.

\begin{tabular}{|c|c|c|c|c|c|c|}
\hline Site & $\begin{array}{c}C_{4} \text { plant } \delta^{13} \mathrm{C} \\
(\% \circ)\end{array}$ & $\begin{array}{c}\mathrm{C}_{4} \text { plant } \delta^{15} \mathrm{~N} \\
(\% \circ)\end{array}$ & $\begin{array}{c}\mathrm{C}_{4} \text { plant } \\
\% \mathrm{~N}\end{array}$ & $\begin{array}{c}C_{3} \text { plant } \delta^{13} C \\
(\% \circ)\end{array}$ & $\begin{array}{l}\mathrm{C}_{3} \text { plant } \\
\delta^{15} \mathrm{~N}(\% \circ)\end{array}$ & $\mathrm{C}_{3}$ plant $\% \mathrm{~N}$ \\
\hline $\begin{array}{c}\text { Omanyne } \\
\text { (OMA) }\end{array}$ & $-15.2 \pm 0.6$ & $11.3 \pm 2.2$ & $1.0 \pm 0.2$ & $-26.6 \pm 1.1$ & $13.0 \pm 2.8$ & $2.5 \pm 0.7$ \\
\hline $\begin{array}{c}\text { Spitzkoppe* } \\
\text { (SPZ) }\end{array}$ & $-12.5 \pm 0.6$ & $3.9 \pm 1.5$ & $0.3 \pm 0.1$ & $-25.8 \pm 1.6$ & $7.1 \pm 3.5$ & $2.0 \pm 0.9$ \\
\hline Zizou (ZIZ) & $-14.0 \pm 0.7$ & $6.6 \pm 0.4$ & $0.6 \pm 0.2$ & $-25.0 \pm 1.6$ & $12.3 \pm 2.0$ & $1.9 \pm 0.9$ \\
\hline NK2010 & $-14.0 \pm 0.7$ & $4.5 \pm 0.5$ & $0.5 \pm 0.2$ & $-27.4 \pm 1.0$ & $7.3 \pm 1.5$ & $1.6 \pm 0.5$ \\
\hline De Rif (DR) & - & - & - & $-26.3 \pm 2.3$ & $1.4 \pm 1.5$ & $0.7 \pm 0.2$ \\
\hline $\begin{array}{l}\text { Pakhuis Pass } \\
\text { (PP) }\end{array}$ & - & - & - & $-26.8 \pm 1.4$ & $2.9 \pm 1.0$ & $0.7 \pm 0.2$ \\
\hline $\begin{array}{l}\text { Jaagvlakte } \\
\text { (JV) }\end{array}$ & - & - & - & $-26.0 \pm 2.7$ & $9.4 \pm 2.4$ & $2.0 \pm 0.6$ \\
\hline
\end{tabular}

913

914

915

916

917 
Table 3: Comparison of faecal and foliar (dietary) $\delta^{15} \mathrm{~N}$ for sites with detailed plant sampling. ${ }^{*}$ refers to sites with differing $\delta^{15} \mathrm{~N}$ in $\mathrm{C}_{3}$ and $\mathrm{C}_{4}$ plants where foliar $\delta^{15} \mathrm{~N}$ is weighted by proportional consumption of $C_{3} / C_{4}$ grasses to derive a dietary $\delta^{15} \mathrm{~N}$ estimate (see text).

\begin{tabular}{|c|c|c|c|c|c|}
\hline Site & Biome & $\begin{array}{l}\text { Average foliar } \\
\text { (dietary) } \delta^{15} \mathrm{~N} \\
(\% \circ)(\mathrm{n})\end{array}$ & $\begin{array}{c}\text { Average } \\
\text { faecal } \delta^{15} \mathrm{~N} \\
(\% \circ)(\mathrm{n})\end{array}$ & $\begin{array}{c}\text { Average } \\
\text { faecal } \mathrm{N} \\
\text { content (\%) }\end{array}$ & $\begin{array}{l}\text { Diet-faeces } \\
\text { offset (\%o) }\end{array}$ \\
\hline NK2010* & Nama Karoo & $6.7 \pm 1.8(14)$ & $7.8 \pm 1.1(19)$ & $1.5 \pm 0.3$ & $1.1 \pm 2.1$ \\
\hline Jaagvlakte (JV) & $\begin{array}{c}\text { Succulent } \\
\text { Karoo }\end{array}$ & $9.4 \pm 2.4$ (8) & $15.5 \pm 2.3(15)$ & $2.6 \pm 1.0$ & $6.1 \pm 3.3$ \\
\hline De Rif (DR) & Fynbos & $1.4 \pm 1.5(7)$ & $3.0 \pm 0.8(12)$ & $2.1 \pm 0.4$ & $1.6 \pm 1.8$ \\
\hline $\begin{array}{c}\text { Pakhuis Pass (PP } \\
2008 / 2013 \text { ) } \\
\end{array}$ & Fynbos & $2.9 \pm 1.0(8)$ & $8.2 \pm 0.8(27)$ & $2.3 \pm 0.3$ & $5.3 \pm 1.3$ \\
\hline $\begin{array}{c}\text { Omanyne* } \\
\text { (OMA) }\end{array}$ & Savanna & $12.5 \pm 2.7(36)$ & $13.5 \pm 1.5(81)$ & $2.2 \pm 0.4$ & $1.0 \pm 3.1$ \\
\hline Zizou* (ZIZ) & Savanna & $8.2 \pm 3.2(13)$ & $7.1 \pm 2.2(48)$ & $1.4 \pm 0.6$ & $-1.1 \pm 3.9$ \\
\hline $\begin{array}{l}\text { Spitzkoppe* } \\
\text { (SPZ) }\end{array}$ & Savanna & $6.2 \pm 3.5(26)$ & $10.3 \pm 1.3(96)$ & $2.5 \pm 0.4$ & $4.1 \pm 3.7$ \\
\hline Average & & & & & $2.6 \pm 2.6$ \\
\hline
\end{tabular}

922 